\title{
Understanding the dechlorination of chlorinated hydrocarbons in the pyrolysis of mixed plastics
}

\author{
Guozhan Jiang ${ }^{1}$, D. A. Sanchez Monsalve ${ }^{2}$, Peter Clough ${ }^{3}$ Ying Jiang ${ }^{3}$, Gary A Leeke ${ }^{1^{*}}$ \\ ${ }^{1}$ School of Chemical Engineering, University of Birmingham, Birmingham B15 2TT, UK \\ ${ }^{2}$ Recycling Technologies Ltd, Unit B2 Stirling Court, Stirling Road, Swindon SN3 4TQ, UK \\ ${ }^{3}$ School of Water Energy and Environment, Cranfield University, Cranfield, Bedfordshire MK43 \\ OAL, UK
}

\begin{abstract}
The dechlorination of chlorine containing hydrocarbons in pyrolysis vapor is poorly understood. In order to shed new light on the dechlorination mechanism, a model mixture composing of isooctane doped with 2-chlorobutane, 2-chloroethylbenzene, and chlorobenzene was used to study the dechlorination of chlorinated hydrocarbons by alkali adsorption. These three chlorinated hydrocarbons were selected as they can be typically produced from the pyrolysis of mixed plastic waste containing polyvinyl chloride (PVC). The mixture is pumped continuously through a $\mathrm{Na}_{2} \mathrm{CO}_{3}$ or $\mathrm{CaCO}_{3} /$ alumina bed, and GC-MS is used to identify the dechlorination products and to follow the dechlorination reactions. When chlorine is bonded to an aliphatic carbon with an adjacent aliphatic hydrogen, the chlorinated compound firstly undergoes a dehydrochlorination reaction to form $\mathrm{HCl}$ and olefins, and subsequently the $\mathrm{HCl}$ is reacted with the alkali in the absorbents. In our experiments, 2-chlorobutane is converted to 2-butene, and 2chloroethylbenzene is converted to styrene. The formation of $\mathrm{HCl}$ and subsequent reaction with
\end{abstract}

${ }^{*}$ Corresponding author. Telephone +44 (0) 121414 4977; Email: G.A.Leeke@bham.ac.uk 
alkali components in the absorbent is verified by IR spectroscopy and XRD. In the presence of an alkali, the aliphatic chlorinated hydrocarbons underwent dechlorination at a temperature of $180^{\circ} \mathrm{C}$. The removal of chlorine from aromatic chlorinated compounds operates in a different mechanism, in which the $\mathrm{C}-\mathrm{Cl}$ bond scission is promoted significantly by the presence of alumina and hydrocarbon medium. It was found that chlorobenzene undergoes dechlorination forming phenol and benzene.

\section{KEY WORDS:}

Dechlorination, chlorinated hydrocarbons, pyrolysis, mixed waste plastics, PVC 


\section{INTRODUCTION}

Pyrolysis recycling of plastic waste is becoming recognized as a viable route for the circular plastic economy where the pyrolysis oil can be cracked and further refined for new plastic production. A problem associated with pyrolysis recycling of mixed plastic waste is the presence of halogen containing components in the waste stream. The primary source of halogens is polyvinyl chloride (PVC), the pyrolysis of which produces $\mathrm{HCl}$ and chlorinated hydrocarbons. For downstream processing of the pyrolysis oil in existing petrochemical plants, chlorine content in the pyrolysis oil must be reduced to less than $10 \mathrm{ppm}$ to prevent unit corrosion. ${ }^{1}$

In commercial pyrolysis of mixed plastic waste containing PVC, a low-temperature pyrolysis between 300 and $330^{\circ} \mathrm{C}$ is used to remove chlorine via dehydrochlorination reactions. ${ }^{2}$ Chlorine cannot be completely removed in this stage since some isolated chlorine atoms are locked inside the remaining structures due to cyclisation and crosslinking with increasing extent of reaction. ${ }^{3}$ Westerhout et al. ${ }^{4}$ estimated that at least $2 \%$ of chlorine went to the next pyrolysis stage. Steam assisted low-temperature pyrolysis can enhance the dehydrochlorination reaction. ${ }^{5,6}$ Recently, Nishibata et al. ${ }^{7}$ investigated dechlorination of PVC plastics using a combination of superheated steam and $\mathrm{CaO}$ to achieve a higher extent of dechlorination. Wet treatment in glycol/ $\mathrm{NaOH}$ mixture is also an effective method to remove chlorine instead of low-temperature pyrolysis pretreatment. ${ }^{8,9}$ Although these new technologies have been developed, capture of chlorine by solid adsorbents during pyrolysis or in subsequent upgrading plastic derived oil is still the dominant technology for reducing chlorine to the required criteria because of its easy operation and low cost. $^{10}$

Alkali adsorbents are widely used either in the pyrolysis reactor or down-stream adsorption. In 1990s, Hinz et al. ${ }^{11}$ carried out a pilot plant scale study of chlorine adsorption by ammonia when running the Hamburg fluidized bed plastic recycling process, which pyrolyzes plastic waste at around $700^{\circ} \mathrm{C}$ to produce gaseous products. The feedstock had a chlorine content of $5 \%$ (wt.), whereas the chlorine content in the derived oil was reduced to between $10 \mathrm{ppm}$ to $1000 \mathrm{ppm}$. The use of limestone $(\mathrm{CaO})$ in the bed was not recommended in this process because of the difficulty in separating the by-product $\mathrm{CaCl}_{2}$ and the bed material. However, the use of limestone or calcium carbonate in the bed can effectively remove chlorine in the produced oil. Cho et al. ${ }^{12}$ used lime, $\mathrm{Ca}(\mathrm{OH})_{2}$ or oyster shell (consisting mainly of $\mathrm{CaCO}_{3}$ ) to adsorb chlorine when 
pyrolyzing mixed plastics containing $1.13 \%$ (wt) chlorine in a $1 \mathrm{~kg} / \mathrm{h}$ fluidized bed reactor at a temperature range between $680^{\circ} \mathrm{C}$ and $780^{\circ} \mathrm{C}$. The resultant oil had a chlorine content of $50 \mathrm{ppm}$. Bhaskar et al. ${ }^{13}$ used $\mathrm{CaCO}_{3}$ supported on carbon to adsorb both chlorine and bromine in a batch reactor for pyrolysis of plastic waste at $430^{\circ} \mathrm{C}$. The feedstock contained $10 \%$ (wt) PVC and $10 \%$ (wt) brominated polystyrene giving a $\mathrm{Cl}$ content of $50000 \mathrm{ppm}$ and a $\mathrm{Br}$ content of $10000 \mathrm{ppm}$. The adsorbent was placed downstream for contacting the pyrolysis vapour. A halogen free liquid was produced when the ratio of $\mathrm{Ca}-\mathrm{C}$ (prepared by the calcination of $90 \mathrm{wt} \% \mathrm{CaCO}_{3}$ and $10 \mathrm{wt} \%$ phenol) to feedstock was 0.4. The difference between the adsorption efficiency in Cho et al's work $^{12}$ and Bhaskar et al's work ${ }^{13}$ may be due to the effect of temperature. It was shown that the binding capacity of $\mathrm{CaO}$ to $\mathrm{HCl}$ peaked at $500-600^{\circ} \mathrm{C}$ in a fluidized bed. ${ }^{14}$ Daoudi and Walters ${ }^{15}$ showed that $\mathrm{CaO}$ conversion levels increased at lower temperatures, because high-temperature results in sintering and thus higher grain diffusion resistance.

Metal oxides are another type of adsorbent for chlorine removal in the pyrolysis of mixed plastic waste. Successful examples include the use of iron oxides such as $\mathrm{Fe}_{2} \mathrm{O}_{3}$ supported on carbon ${ }^{16}$ or $\mathrm{SiO}_{2}{ }^{17}, \mathrm{Fe}_{3} \mathrm{O}_{4}{ }^{18}$, and $\mathrm{FeOOH} .{ }^{19}$ Over these adsorbents, the adsorption is often carried out at around $300-350^{\circ} \mathrm{C}$ with a chlorine conversion of greater than $80 \%$, with iron oxide being converted to iron chloride when iron oxides were used. In batch operation with red mud (composed mainly of $\mathrm{Fe}_{2} \mathrm{O}_{3}$ ), Lopez et al ${ }^{20}$ reported that the chlorine content in the liquid stream reduced from $2000 \mathrm{ppm}$ to $10 \mathrm{ppm}$ when processed at $325^{\circ} \mathrm{C}$ with a dwell time of $30 \mathrm{~min}$. Other metal oxides have also been tested to adsorb chlorine from mixed plastics-derived oil such as $\mathrm{ZnO}$ and $\mathrm{MgO}$ and achieved limited success. ${ }^{19}$

In these reports, the nature of the chlorine was not clearly stated. The mechanism for the adsorption of $\mathrm{HCl}$ by alkali or metal oxides is clearly an acid-base neutralisation reaction. However, the dechlorination of the chlorinated hydrocarbons, has not so far been elucidated. In this work, we aim to understand how the chlorinated hydrocarbons can be dechlorinated by alkali adsorption, especially in the presence of hydrocarbons. An insight into dechlorination of chlorinated hydrocarbons will be beneficial for designing effective chlorine sorbents. Efficient adsorbents can both be used to adsorb chlorine from pyrolysis vapour or from pyrolysis oil and therefore provide a chlorine free oil for downstream processing, aiding in the overall success of plastic-to-fuel or plastic-to-plastic technology. 
In a commercial plastic waste pyrolysis system, the chlorinated hydrocarbons are mixed with other hydrocarbons in the pyrolysis vapour. We investigated this problem using a model system composing of isooctane doped with the two types of chlorinated compounds, which were elected from the list of chlorinated hydrocarbons obtained from pyrolysis of plastic waste containing PVC. A systematic investigation by McNeill et al. ${ }^{21}$ and Miranda et al. ${ }^{22,23}$ provides a detailed list of the chlorinated hydrocarbons that can be produced during pyrolysis of PVC or mixed plastic waste containing PVC. The chlorinated hydrocarbons in the list can be classified into two categories: aliphatic, in which the chlorine atom is bonded with an aliphatic carbon, and aromatic, in which the chlorine atom is bonded with an aromatic carbon. Three chlorinated hydrocarbons were elected from the list of Miranda et al. ${ }^{22,23}$ : 2-chlorobutane (aliphatic), 2chloroethylbenzene (aliphatic with a benzene ring), and chlorobenzene (aromatic). The isooctane was selected to represent the light-end compounds in the plastic-derived oil.

\section{EXPERIMENTAL}

\section{Chemicals}

The three chlorinated hydrocarbons, 2-chlorobutane ( $\geq 99 \%)$, 2-chloroethylbenzene $(\geq 99 \%)$ and chlorobenzene (anhydrous, 99.8\%), and the hydrocarbon medium 2,2,3-trimethylpentane (isooctane) (anhydrous, 99.8\%) were purchased from Sigma-Aldrich (UK) and used as received. The adsorbents used in this work were $\mathrm{Na}_{2} \mathrm{CO}_{3}$ and $\mathrm{CaCO}_{3}$ from Sigma-Aldrich UK (Anhydrous, $\geq 99.5 \%$ ) and Longcliffe UK ( $\geq 98 \%$ ), respectively, and used as received. Alumina pellets (2 $\mathrm{mm}$ ) were obtained from Fisher Scientific UK and used as the support. Silicon carbide (SiC) (200 mesh) obtained from Sigma-Aldrich UK was used as the support for the adsorption bed.

\section{Experimental procedure}

A schematic diagram of the experimental rig is shown in Figure 1. The continuous flow rig consisted of a feedstock bottle (5L), a HPLC pump (Jasco PU-1586 Intelligent Prep Pump), a tubular flow reactor $(600 \mathrm{~mm} \times 1 / 2$ " 316 stainless steel tube from Swagelok), a condenser, a gasliquid separator, a sampling valve, and a collection bottle $(5 \mathrm{~L})$. The tube reactor was placed vertically in a Carbolite ${ }^{\mathrm{TM}}$ tube furnace (Model EVA 12/450). 
The reactor had three sections: $\mathrm{SiC}$ (-200 mesh, Sigma-Aldrich) in the lower part, the absorbent bed in the middle (in the uniform heating zone), and $\mathrm{SiC}$ on top of the adsorbent bed. A thin layer of glasswool was placed to separate each section and facilitate later collection of the adsorbent. SiC was used to support the adsorption bed and enabled a uniform wetting of the bed. ${ }^{24}$ Before an adsorption experiment, the system was pressurized with nitrogen to $10 \mathrm{bar}$ for a gastight test and then flushed using nitrogen to remove air in the system. After nitrogen flushing, the adsorption column was heated to a desired temperature, which was monitored by the thermocouples T1 and T2. When the temperature reached the desired value and stabilized for about 30 minutes, the HPLC pump was started to pump isooctane solution containing the chlorine compounds each with a concentration of $10000 \mathrm{ppm}(\mathrm{wt})$ from the feedstock bottle into the top of the adsorption column. The vapour coming out of the bottom of the bed was condensed in the condenser, and then went to the collection bottle after a gas-liquid separator. The non-condensable gas was vented to an extraction system.

After an adsorption experiment, $\mathrm{Na}_{2} \mathrm{CO}_{3}$ or $\mathrm{CaCO}_{3}$ were separated from the alumina. The separated adsorbent was kept in a pre-dried glass vial for further analysis. It was easy to perform the separation since both $\mathrm{Na}_{2} \mathrm{CO}_{3}$ and $\mathrm{CaCO}_{3}$ were fine particles, and alumina was in pellet form. 


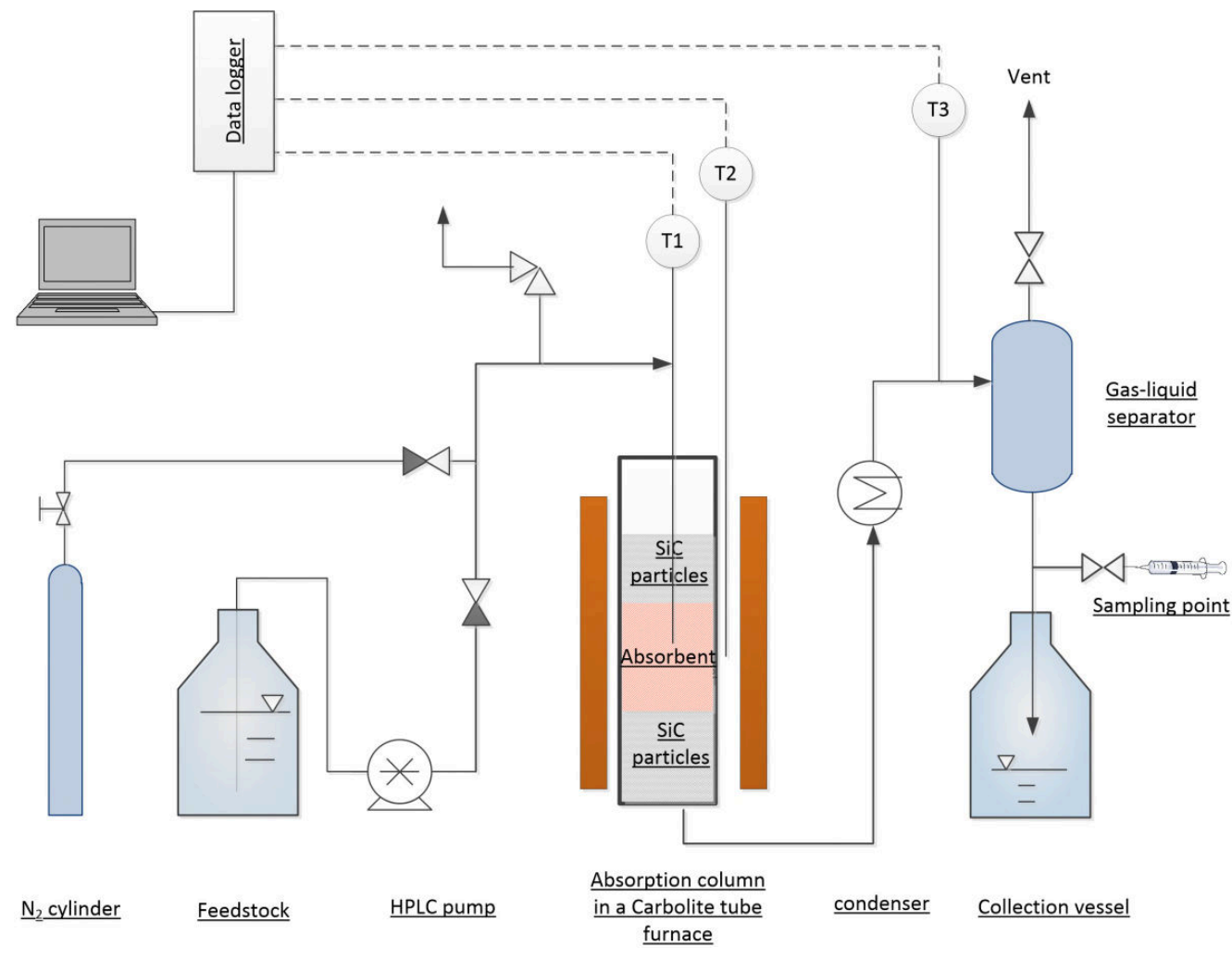

Figure 1. A schematic diagram for the continuous flow adsorption rig

Two types of experiments were conducted: staged heating adsorption and isothermal adsorption. In staged heating adsorption, the adsorbent bed was heated to a temperature and then kept at that temperature for $10 \mathrm{~min}$, and then the temperature of the column was increased to higher temperatures in $20^{\circ} \mathrm{C}$ steps and held isothermally for 10 minutes at each step to about $550^{\circ} \mathrm{C}$. A solution containing $10000 \mathrm{ppm}(\mathrm{wt})$ of single or mixed chlorinated hydrocarbons in isooctane was passed through the bed at a liquid flow rate of $2 \mathrm{ml} / \mathrm{min}$. This flow rate was determined by the liquid space velocity (LSV) so that sufficient residence time was provided for the dechlorination process (Figures S1 to S2). Samples were taken at each temperature step from the outlet liquid and were subsequently analysed by GC test to determine the reaction products. The staged adsorption experiment was used to determine the adsorption temperature of a chlorinated hydrocarbon compound.

In the isothermal adsorption experiment, the adsorbent bed was heated to a pre-determined temperature and kept at that temperature. A chlorinated hydrocarbon in isooctane solution with a concentration of $10000 \mathrm{ppm}(\mathrm{wt})$ each passed through the bed at a flow rate of $2 \mathrm{ml} / \mathrm{min}$ until a 
breakthrough point was reached, where chlorinated hydrocarbons were detected in the exit solution. The isothermal adsorption experiment was used to determine the adsorption capacity of the adsorbent.

The adsorption process of a chlorinated hydrocarbon was followed using GC/MS by monitoring the ratio of outlet to inlet peak area of the corresponding chlorinated hydrocarbons, which is equivalent to the ratio of the outlet to inlet concentration. The measurement error of the peak area is less than $6 \%$ under the conditions of the GC/MS, which is propagated to an error of $8 \%$ of the area ratio.

\section{Analysis procedure}

The reaction products were identified and quantified using GCMS. The GCMS consists of a Perkin Elmer Clarus 680GC hyphenated with a Clarus SQ8T mass spectrometer, equipped with an auto-sampler and a $30 \mathrm{~m}$ long Perkin Elmer Elite-5 capillary column. A full scan mode was used and then the peak areas of proper quantitation ions were measured for the compounds of interest.

Infrared spectroscopy was used to observe the changes in the vibrational spectra of the adsorbent after absorbing the chlorinated hydrocarbons. The adsorbents were crushed into powder form before analysis. The spectra were acquired using a Shimadzu Tracer 100 FTIR-ATR facility over a spectral range of 4000-600 $\mathrm{cm}^{-1}$ with 16 times of scan and a resolution of $4 \mathrm{~cm}^{-1}$.

The presence of inorganic chlorinated compounds in the adsorbents was determined using X-ray diffraction (XRD) on a Siemens D5005 diffractometer with $\mathrm{Cu}$ K $\alpha$ radiation $(\lambda=1.5418 \AA)$ at room temperature. The XRD was operated at $40 \mathrm{kV}$ and $40 \mathrm{~mA}$ with the scan rate of $0.04 \%$ over the $2 \theta$ range from $20-90^{\circ}$. Diffrac.EVA V4.1 was used to analyse the XRD patterns.

\section{RESULTS AND DISCUSSION}

\section{Thermal effect on dechlorination}

A blank experiment was conducted in the absence of adsorbents to investigate the dechlorination behaviour of these chlorinated hydrocarbons at elevated temperatures in the isooctane medium, 
in which the adsorbent bed consisted of only $\mathrm{SiC}$, a chemically inert material ${ }^{25}$. The variation of GC peak area of the chlorinated hydrocarbons and their decomposition products in the outlet stream are plotted against temperature in Figure 2.
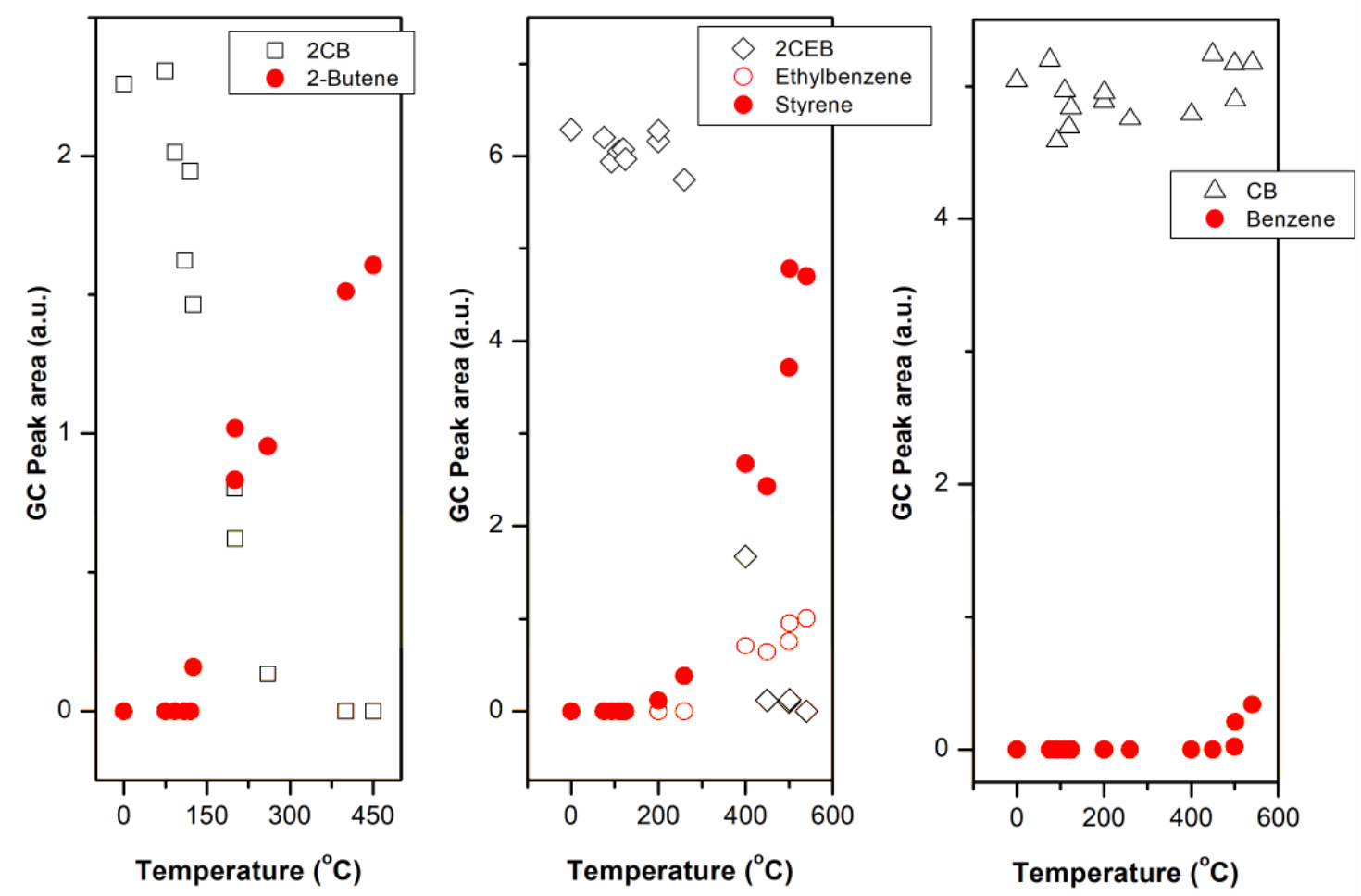

Figure 2. The influence of temperature on the thermal decomposition of chlorinated hydrocarbons in isooctane. The concentrations of 2-chlorobutane (2CB), 2-chloroethylbenzene (2CEB) and chlorobenzene (CB) in the inlet stream were 10000 ppm (wt.), respectively. No other compounds were detected in the GC chromatogram.

For 2-chlorobutane solution passing through the reactor, only 2-chlorobutane was detected at the outlet stream before $125^{\circ} \mathrm{C}$. 2-Butene was first detected at $125^{\circ} \mathrm{C}$, which is clearly the dehydrochlorination product of 2-chlorobutane as shown in Scheme 1. With increasing temperature, the concentration of 2-chlorobutane decreases and 2-butene increases rapidly. When the temperature reaches $200^{\circ} \mathrm{C}, 2$-chlorobutane concentration in the outlet stream drops to about $50 \%$ of the inlet concentration. When the temperature reaches $350^{\circ} \mathrm{C}, 2$-chlorobutane is not detectable in the outlet stream, and the concentration of 2-butene reaches a maximum value. 
At about $200^{\circ} \mathrm{C}$, styrene is detected in the outlet stream for 2-chloroethylbenzene solution, which is clearly the dehydrochlorination product of 2-chloroethylbenzene as shown in Scheme 2. With increasing temperature, the concentration of 2-chloroethylbenzene in the outlet stream decreases and styrene concentration increases correspondingly. At $400^{\circ} \mathrm{C}$, the concentration of 2 chloroethylbenzene drops to about $30 \%$ of that of the inlet solution. In the meantime, ethylbenzene is detected in the outlet stream, which should be a secondary reaction product of styrene. However, 2-chloroethylbenzene can still be detected in the outlet stream even at $550^{\circ} \mathrm{C}$, although the concentration is only about $2 \%$ of that in the inlet concentration. It can be seen here that 2-chloroethylbenzene is more difficult to be dehydrochlorinated.

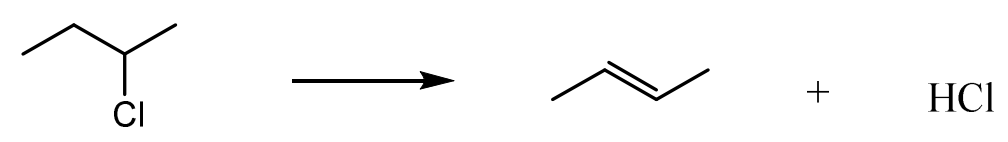

Scheme 1. Dehydrochlorination of 2-chlorobutane.

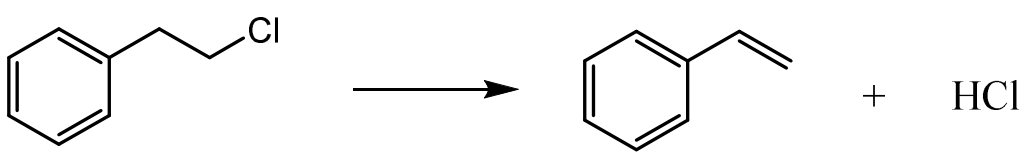

Scheme 2. Dehydrochlorination of 2-chlorobutane.

No decomposition products are detected until $500^{\circ} \mathrm{C}$ for chlorobenzene solution. At $500^{\circ} \mathrm{C}$, a trace amount of benzene is detected in the outlet stream, indicating that there is a decomposition of chlorobenzene at this temperature. However, the extent of decomposition is quite small. When the temperature is raised up to $550^{\circ} \mathrm{C}$, the concentration of chlorobenzene in the outlet stream is similar to that at $500^{\circ} \mathrm{C}$. Cullis et al. ${ }^{26}$ reported a minimum thermal decomposition temperature of $740^{\circ} \mathrm{C}$ for chlorobenzene, mainly via stripping of the aromatic rings forming benzene. Li et al. ${ }^{27}$ reported that chlorobenzene does not undergo decomposition below $600^{\circ} \mathrm{C}$ in an inert gas, but there is a small extent of decomposition in hydrogen at $500^{\circ} \mathrm{C}$. In this work, the reaction medium is isooctane, which may promote a thermal decomposition at around $500^{\circ} \mathrm{C}$ producing trace amount of benzene, as discussed in the following mechanism section. 


\section{$\mathrm{Na}_{2} \mathrm{CO}_{3}$ effect on dechlorination}

From the above results, where only thermal treatment was used, the chlorine in 2-chlorobutane and in 2-chloroethylbenzene can be removed via dehydrochlorination starting from $125^{\circ} \mathrm{C}$ and $200^{\circ} \mathrm{C}$, respectively, whereas the chlorine in chlorobenzene cannot be removed below $500^{\circ} \mathrm{C}$. The chlorine removed would be in the form of $\mathrm{HCl}$ and exit from the outlet stream. An alkali adsorbent can therefore be used to adsorb the $\mathrm{HCl}$. In order to test the effect of alkali adsorbents, isothermal adsorption experiments were performed at various temperatures. Isothermal adsorption of the three chlorinated hydrocarbons in isooctane was conducted using a mixture of $\mathrm{Na}_{2} \mathrm{CO}_{3} / \mathrm{Al}_{2} \mathrm{O}_{3}$ pellets. A typical GCMS chromatogram is shown in Figure 3 for the adsorption at $180^{\circ} \mathrm{C}$ and $450^{\circ} \mathrm{C}$, and typical adsorption curves are plotted in Figure 4 . The adsorption curve for other temperatures are similar and shown in Figures S3-S6.

Figure 3 shows that there are three peaks for the three chlorinated hydrocarbons in the inlet stream (Figure 3A). After passing through the adsorption bed at $180^{\circ} \mathrm{C}$ (Figure 3B), the peak for chlorobenzene remains, but the peaks for 2-chlorobutane and 2-chloroethylbenzene disappear. Instead, two new peaks appear at $1.53 \mathrm{~min}$ and $5.37 \mathrm{~min}$, which were identified as 2-butene and styrene, respectively. According to the products, 2-chlorobutane and 2-chloroethylbenzene undergo dehydrochlorination reactions as in the blank test.

When the solution passes through the adsorption bed at $450^{\circ} \mathrm{C}$ (Figure 3C), three other peaks appear at $2.25 \mathrm{~min}, 4.80 \mathrm{~min}$ and $7.34 \mathrm{~min}$, which were identified as benzene, ethylbenzene and phenol, respectively. According to structural similarity, ethylbenzene is a reaction product of styrene at $450^{\circ} \mathrm{C}$. Benzene and phenol are the reaction products of chlorobenzene. Besides these peaks attributed to the adsorption of chlorinated hydrocarbons, there are small peaks at $2.02 \mathrm{~min}$ and $1.44 \mathrm{~min}$. These peaks are light aliphatic hydrocarbons (butane and isobutane, $1.44 \mathrm{~min}, 1.42$ $\mathrm{min})$, which are attributed to cracking of isooctane. ${ }^{28}$ 

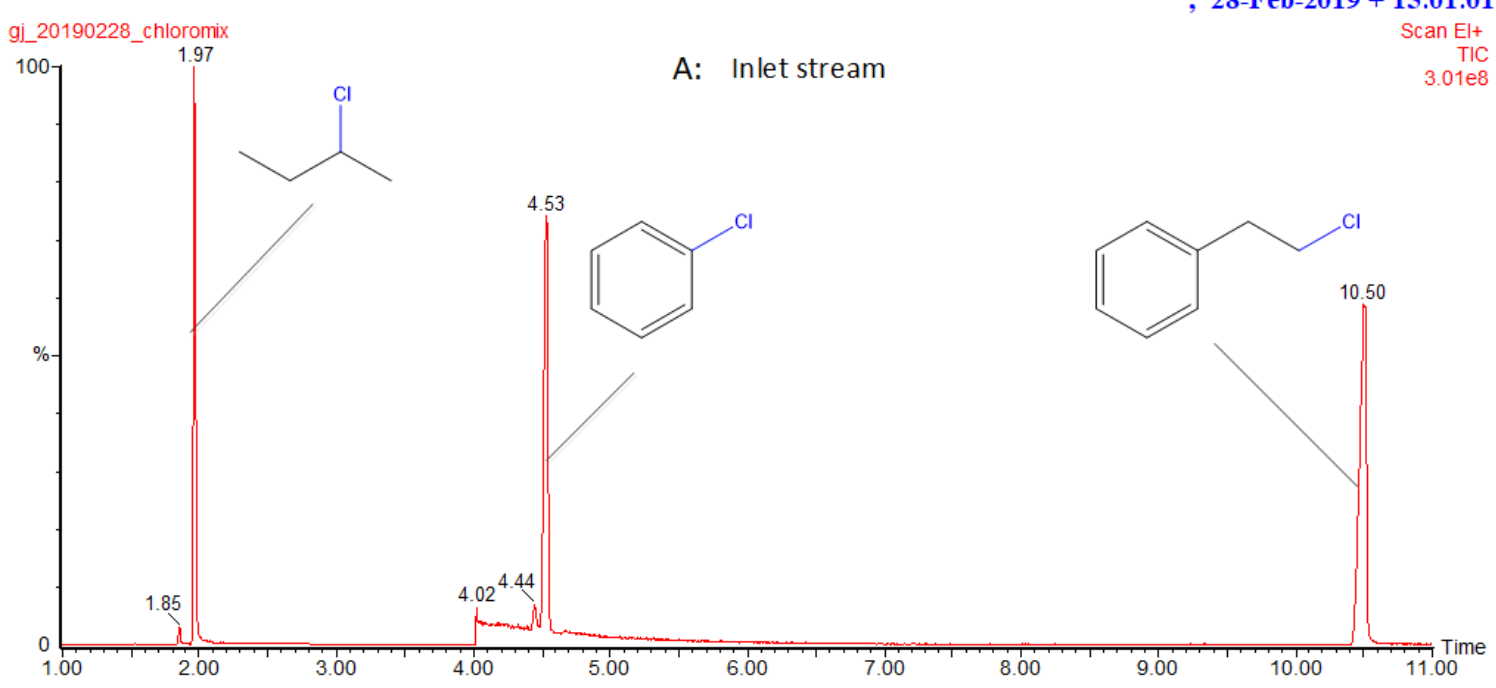

gj_20190220_150min

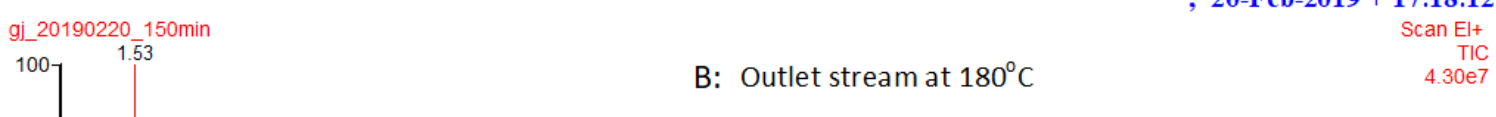

Scan El+
TIC
$4.30 \mathrm{e} 7$
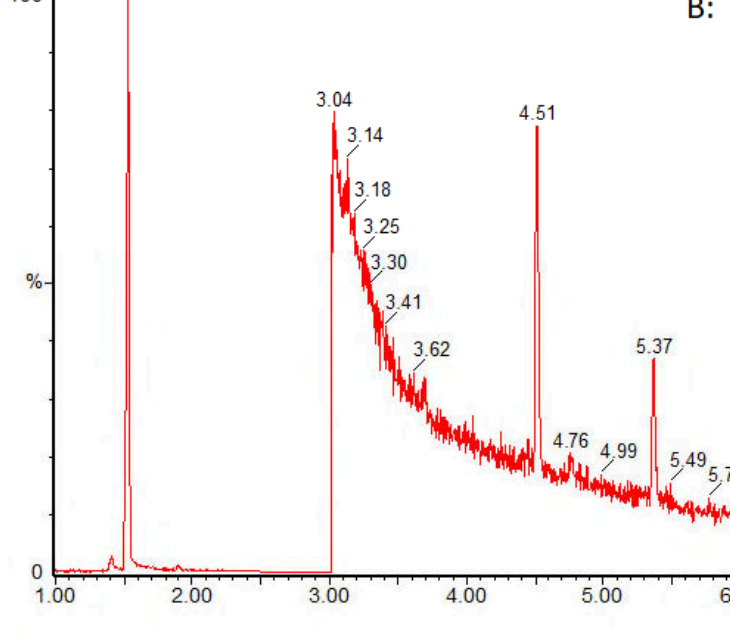

$6.356,50 \quad 6.88$

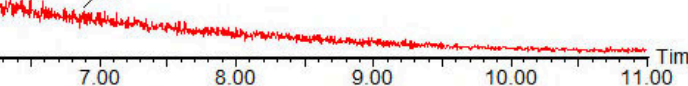

gj_20190301_200

100

C: Outlet stream at $450^{\circ} \mathrm{C}$

, 01-Mar-2019 + 14:24:43

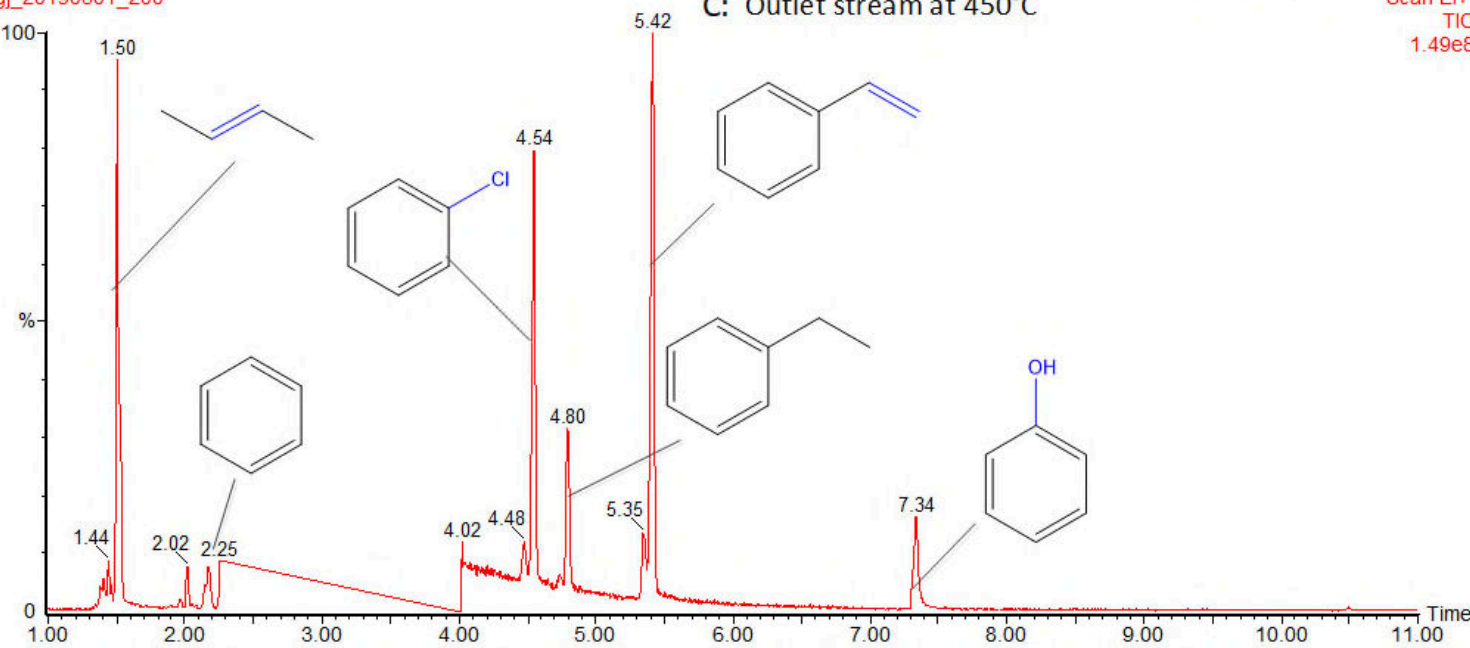


Figure 3. Typical GCMS chromatograms of inlet (A) and outlet stream (B and C) for the adsorption of the chlorinated hydrocarbons on $\mathrm{Na}_{2} \mathrm{CO}_{3} / \mathrm{Al}_{2} \mathrm{O}_{3}$ at $180^{\circ} \mathrm{C}(\mathrm{B})$ and $450^{\circ} \mathrm{C}(\mathrm{C})$. The liquid flow rate was $2 \mathrm{ml} / \mathrm{min}$. Initial concentrations of the chlorinated hydrocarbons were $10000 \mathrm{ppm}(\mathrm{wt})$, respectively.

As shown in Figure 4, 2-chlorobutane and 2-chloroethylbenzene are not detected in the outlet stream for the first $50 \mathrm{~min}$ at $180^{\circ} \mathrm{C}$. After $50 \mathrm{~min}$, both 2-chlorobutane and 2chloroethylbenzene are detected with a concentration of 5\% of that of the inlet concentration, and then the concentrations of the two aliphatic chlorinated hydrocarbons increases gradually. This indicates that the $\mathrm{Na}_{2} \mathrm{CO}_{3}$ bed starts to become saturated at about 50 min on stream.
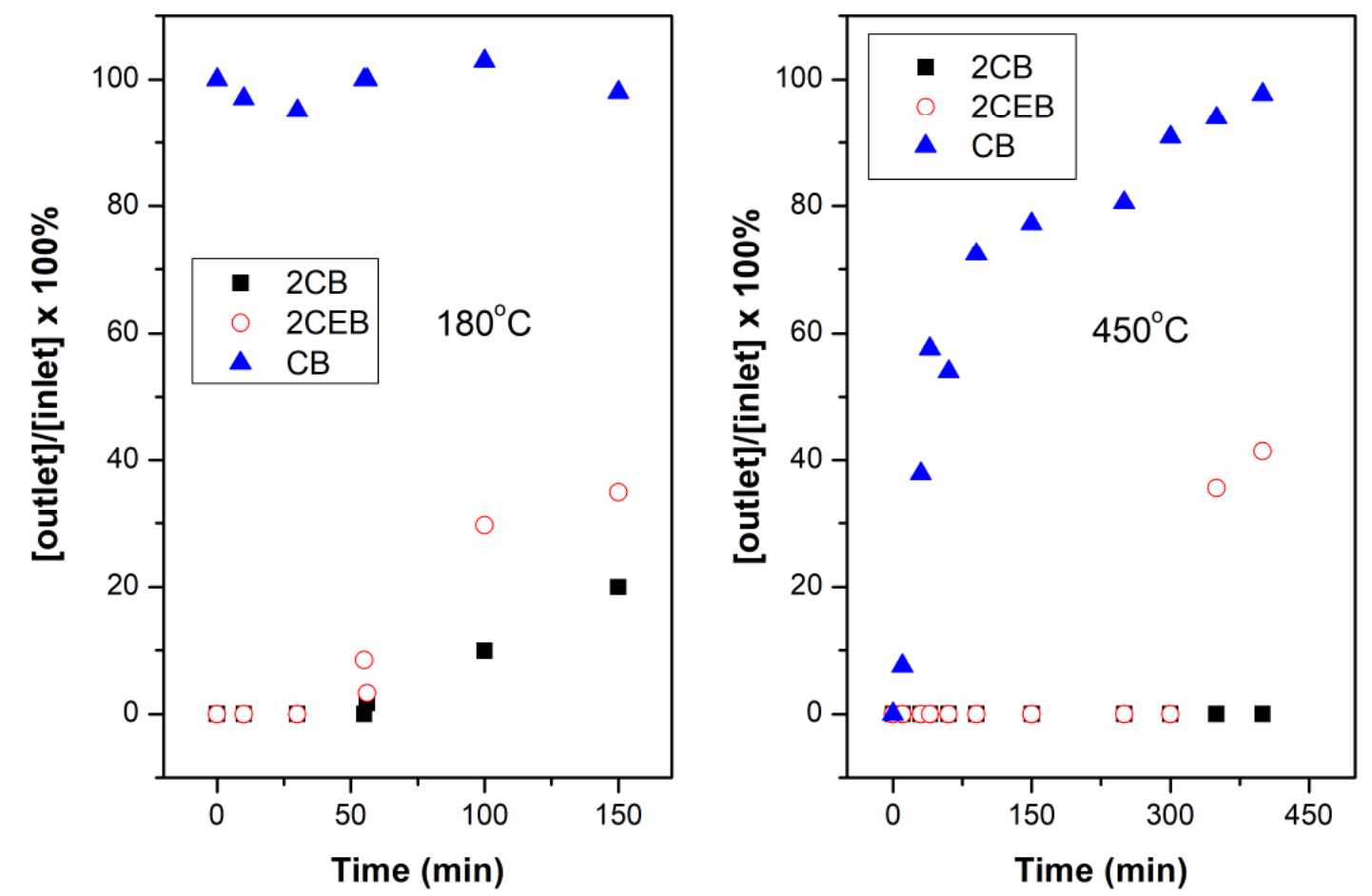

Figure 4. Co-adsorption of the three chlorinated hydrocarbons in isooctane at different temperatures. The adsorbent bed consisted of a mixture $3 \mathrm{~g} \mathrm{Na}_{2} \mathrm{CO}_{3}$ and $12 \mathrm{ml}(4.72 \mathrm{~g}$ ) alumina pellets for the adsorption at $180^{\circ} \mathrm{C}$ and a mixture of $10 \mathrm{~g} \mathrm{Na}_{2} \mathrm{CO}_{3}$ and $30 \mathrm{ml}(11.8 \mathrm{~g})$ alumina pellets for the adsorption at $450^{\circ} \mathrm{C}$, and the inlet liquid flow rate is $2 \mathrm{ml} / \mathrm{min}$. The concentrations of 2-chlorobutane (2-CB), 2-chloroethylbenzene (2-CEB) and chlorobenzene (CB) were 10000 ppm (wt), respectively. 
For an adsorption temperature of $450^{\circ} \mathrm{C}$, the adsorption bed consists of $10 \mathrm{~g} \mathrm{Na}_{2} \mathrm{CO}_{3}$ and $25 \mathrm{ml}$ $(9.8 \mathrm{~g}) \mathrm{Al}_{2} \mathrm{O}_{3}$ pellets. This increased mass allowed the adsorption behaviour to be observed over a longer time. Both 2-chlorobutane and 2-chloroethylbenzene were not detected for the first 300 minutes. After about 300 minutes, 2-chloroethyl benzene was detected at the outlet, indicating that the adsorbent starts to become saturated. However, the breakthrough time of 2-chlorobutane does not appear when compared to the test at $180^{\circ} \mathrm{C}$. This is most probably due to the chemical equilibrium strongly favouring the formation of 2-butene at $450^{\circ} \mathrm{C}$. The reaction will proceed according to Scheme 1 in the absence of $\mathrm{Na}_{2} \mathrm{CO}_{3}$. The reaction equilibrium constant of Scheme 1 at $450^{\circ} \mathrm{C}$ was calculated according to Equation 1.

$$
K=\ln \left(\frac{-\Delta G_{r}}{R T}\right)
$$

Where $\Delta \mathrm{G}_{\mathrm{r}}$ is the Gibbs energy change of the reaction, $\mathrm{R}$ is the gas constant, and $\mathrm{T}$ is the temperature. According to the thermochemical data of the reactant and products (from Lange's Handbook of Chemistry), $\mathrm{K}=206$ at $450^{\circ} \mathrm{C}$. This suggests that the equilibrium concentration of 2 -butene is only $6 \%$ to that of 2-chlorobutane. Consequently, the breakthrough time may not be observed at this point. The favourable presence of 2-butene for the equilibrium of 2chlorobutane and 2-butane and $\mathrm{HCl}$ can also be seen from Figure 2, where 2-chlorobutane was not detectable at $450^{\circ} \mathrm{C}$ in the absence of any adsorbents.

It can be seen that the products are the same whether the two aliphatic chlorinated hydrocarbons pass through a bed of $\mathrm{Na}_{2} \mathrm{CO}_{3}$ or not. Under both conditions, 2-butene and styrene are formed, respectively. The difference between the two conditions is that the dehydrochlorination temperature was lowered when $\mathrm{Na}_{2} \mathrm{CO}_{3}$ was used. It has been shown in the blank test that dehydrochlorination reactions of 2-chlorobutane start at about $125^{\circ} \mathrm{C}$. At $180^{\circ} \mathrm{C}$, about $50 \%$ of 2chlorobutane was thermally converted to 2-butene, as shown in Figure 2. When 2-chlorobutane passes through an adsorption bed of $\mathrm{Na}_{2} \mathrm{CO}_{3}$ with the same space velocity, all the 2-chlorobutane is converted to 2-butene. There was no thermal dehydrochlorination of 2-chloroethylbenzene at $180^{\circ} \mathrm{C}$, but the conversion of 2-chloroethylbenzene to styrene is completed in the presence of $\mathrm{Na}_{2} \mathrm{CO}_{3}$ at this temperature. An overall reaction as shown in Schemes 3 and 4 can be drawn for the dehydrochlorination in the presence of $\mathrm{Na}_{2} \mathrm{CO}_{3}$. 


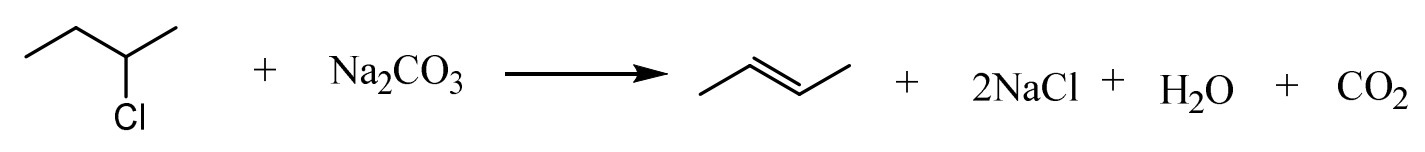

Scheme 3. Dehydrochlorination of 2-chlorobutane in the presence of $\mathrm{Na}_{2} \mathrm{CO}_{3}$.

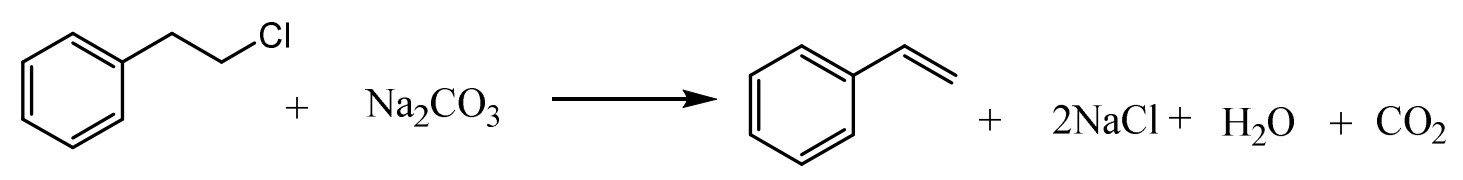

Scheme 4. Scheme 3. Dehydrochlorination of 2-chlorobutane in the presence of $\mathrm{Na}_{2} \mathrm{CO}_{3}$.

The change of the mass of the adsorbent before and after adsorption experiments was calculated using Equation (1) according to Schemes 3 and 4, which indicates that when 1 mole of the adsorbate is converted, the increase in the mass of the adsorbent is equivalent to the mass difference of 2 mole $\mathrm{Cl}^{-}$and 1 mole of $\mathrm{CO}_{3}{ }^{2-}$.

$w=\left(\frac{V \rho C_{2 C B}}{M W_{2 C B}}+\frac{V \rho C_{2 C E B}}{M W_{2 C E B}}\right) \times(71-60) / 2$

Where $\mathrm{V}$ is the solution volume passing through the adsorption bed, $\rho$ is the density of isooctane, $\mathrm{C}$ is the concentration of adsorbate, and MW is the molar mass, 71 is the relative molar mass (RMM) of $2 \mathrm{Cl}^{-}$, and 60 is the $\mathrm{RMM}$ of $\mathrm{CO}_{3}{ }^{2-}$. The subscripts $2 \mathrm{CB}$ and $2 \mathrm{CEB}$ represents $2-$ chlorobutane and 2-chloroethylbenzene, respectively.

The results are, compared with the measured mass changes in Table 1. It can be seen that for 2chlorobutane and 2-chloroethylbenzene, the mass change of the adsorbent is very close to the calculated mass change according to the schemes. It can therefore be considered that the dechlorination process is via dehydrochlorination reactions. However, there is a large discrepancy between the mass change and the calculated mass change. The calculation of chlorobenzene adsorption was based on the exchange of the chlorine and oxygen atom using Equation (2) and is discussed in the following mechanism section.

$w=\left(\frac{V \rho C_{C B}}{M W_{C B}}\right) \times(35.5-16)$ 
Where $\mathrm{V}$ is the solution volume passing through the adsorption bed, $\rho$ is the density of isooctane, $\mathrm{C}$ is the concentration of adsorbate, and MW is the molar mass, 35.5 is the RMM of chlorine, and 16 is the RMM of oxygen. The subscripts CB represents chlorobenzene.

Table 1. Comparison of adsorbent mass changes and calculated mass changes according to Schemes 3 and 4.

\begin{tabular}{|llllll} 
Exp.\# & Adsorbent & $\begin{array}{l}\text { Temperature } \\
\left({ }^{\circ} \mathrm{C}\right)\end{array}$ & $\begin{array}{l}\text { Measured mass } \\
\text { change }(\mathrm{g})\end{array}$ & $\begin{array}{l}\text { Calculated mass } \\
\text { change }(\mathrm{g})\end{array}$ \\
\hline $\mathbf{2 2 0}$ & $\mathrm{Na}_{2} \mathrm{CO}_{3}$ & 180 & $2 \mathrm{CB}+2 \mathrm{CEB}$ & 0.1154 & 0.0956 \\
$\mathbf{2 2 7}$ & $\mathrm{Na}_{2} \mathrm{CO}_{3}$ & 250 & $2 \mathrm{CB}+2 \mathrm{CEB}$ & 0.5202 & 0.5792 \\
\hline $\mathbf{3 2 9}$ & $\mathrm{Na}_{2} \mathrm{CO}_{3}$ & 450 & $\mathrm{CB}$ & 0.3402 & 0.6775 \\
\hline
\end{tabular}

The isothermal adsorption of chlorobenzene is quite different to those of the two aliphatic chlorinated hydrocarbons. At $180^{\circ} \mathrm{C}$, the outlet concentration of chlorobenzene does not show a significant change compared with that of the inlet stream, which indicates that chlorobenzene cannot be dechlorinated at this temperature. At $450^{\circ} \mathrm{C}$, the concentration of chlorobenzene of the outlet stream drops to about $5 \%$ of the inlet stream concentration at the start, and then increases gradually to nearly the same as that of the inlet stream concentration over $400 \mathrm{~min}$, indicating that chlorobenzene can be dechlorinated at $450^{\circ} \mathrm{C}$. However, the breakthrough time is much shorter than that of the two aliphatic chlorinated hydrocarbons.

It can also be seen from Figure 4 that the adsorption of 2-chlorobutane and 2-chloroethylbenzene is not affected by the adsorption of chlorobenzene. Although the adsorption of chlorobenzene slows down gradually, the adsorption of the two chlorinated compounds continues without any interruption. This behaviour indicates that two different mechanisms of dechlorination are operating for the adsorption of 2-chlorobutane and 2-chloroethylbenzene, and for the adsorption of chlorobenzene. This is reasonable since chlorobenzene has no aliphatic hydrogen adjacent to chlorine to affect its ability to leave and form $\mathrm{HCl}$ and an olefin. The very short breakthrough time for chlorobenzene suggests that the adsorption of chlorobenzene proceeds mainly on the surface with the interior of the adsorbents is probably not accessed. When the $\mathrm{Na}_{2} \mathrm{CO}_{3}$ surface is used up and the interior is covered by the chemisorbed product, the dechlorination reaction stops. 
The dechlorination of chlorobenzene proceeds at $450^{\circ} \mathrm{C}$ in this study. This temperature is much lower than those reported in the previous work of Parrett et al. ${ }^{29}$ They reported a minimum adsorption temperature of $600^{\circ} \mathrm{C}$ for the adsorption of chlorobenzene on $\mathrm{Na}_{2} \mathrm{CO}_{3}$ in the absence of a carrier gas. Li et al. ${ }^{27}$ conducted chlorobenzene adsorption on nanoscale $\mathrm{CaO}$ using various carrier gases. When the carrier gas was helium, adsorption was detected at $700^{\circ} \mathrm{C}$, however when the carrier gas was hydrogen, the adsorption was detected at $500^{\circ} \mathrm{C}$, with an extent of decomposition of about $10 \%$. The reduction in adsorption temperature may be attributed to the reduction by hydrogen. These research works indicate that the adsorption medium has an influence on the reaction temperature. The much lower reaction temperature of adsorbing chlorobenzene in this work suggests that the presence of alumina and isooctane has promoted the adsorption. In the following, the effects of alumina and $\mathrm{Na}_{2} \mathrm{CO}_{3}$ on the dechlorination of chlorobenzene is investigated to seek deeper insight into the adsorption of chlorobenzene.

\section{Dechlorination of chlorobenzene}

Figure 5 shows the chlorobenzene concentration ratio of outlet to inlet stream with adsorption temperature when a solution of chlorobenzene in isooctane was passed through different adsorbent beds. It can be seen that alumina and $\mathrm{Na}_{2} \mathrm{CO}_{3}$ has no dechlorination effect on chlorobenzene from room temperature to $550^{\circ} \mathrm{C}$ when they are used alone. However, chlorobenzene is dechlorinated when the solution passed through a bed of $\mathrm{Na}_{2} \mathrm{CO}_{3}$ mixed with alumina at about $300^{\circ} \mathrm{C}$. The dechlorination products are benzene and phenol, as shown in Figure 6, a typical chromatogram for the adsorption process. The higher the temperature, the more dechlorination takes place; at $410^{\circ} \mathrm{C}$, the dechlorination is about $90 \%$. It can be concluded that $\mathrm{Al}_{2} \mathrm{O}_{3}$ combined with $\mathrm{Na}_{2} \mathrm{CO}_{3}$ can enhance the dechlorination of chlorobenzene. Further increases in temperature results in an increase in the outlet concentration of chlorobenzene. This can be considered a breakthrough point of the adsorption bed of $\mathrm{Na}_{2} \mathrm{CO}_{3} /$ alumina indicating when all the alkali has been consumed. 


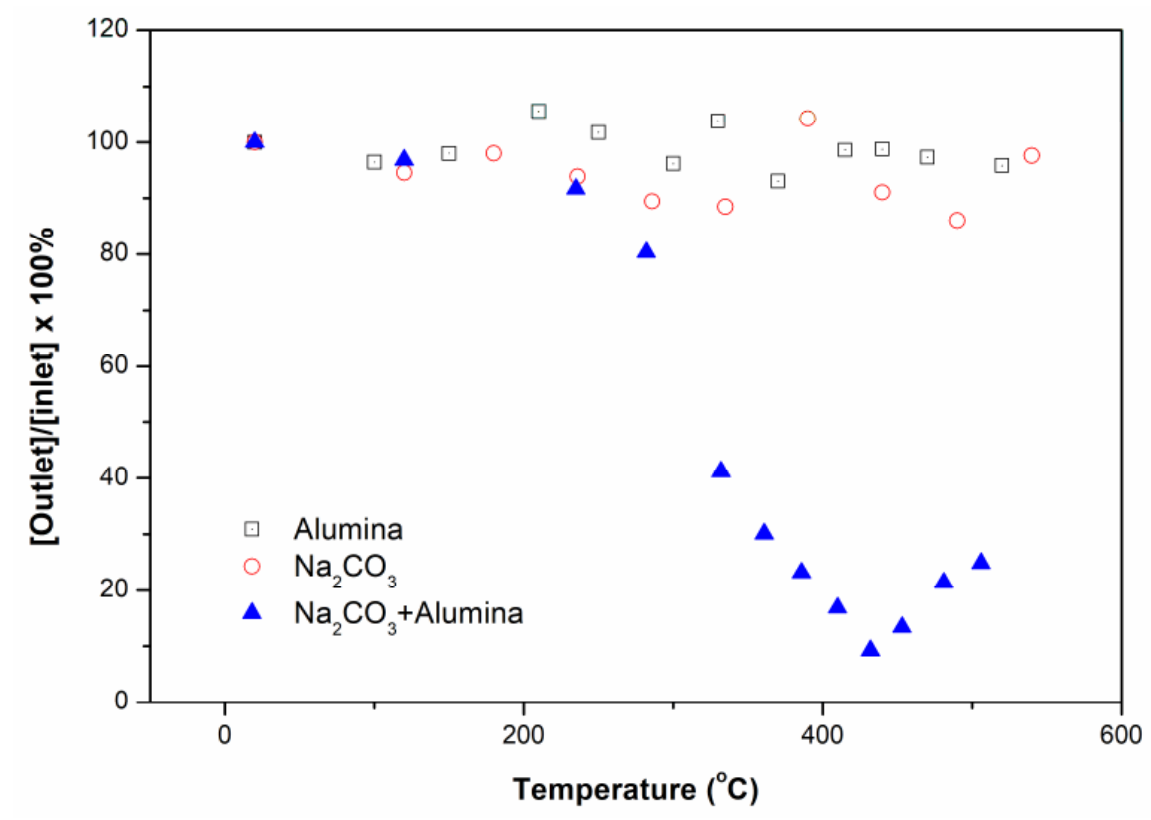

Figure 5. Dechlorination of chlorobenzene over different adsorption beds and temperatures. The concentration of chlorobenzene in isooctane was 10000 ppm (wt.). The inlet liquid flow rate was $2 \mathrm{ml} / \mathrm{min}$. The bed consisted of $3 \mathrm{~g} \mathrm{Na}_{2} \mathrm{CO}_{3}$ or $12 \mathrm{ml}(4.7 \mathrm{~g})$ alumina or their mixture. 


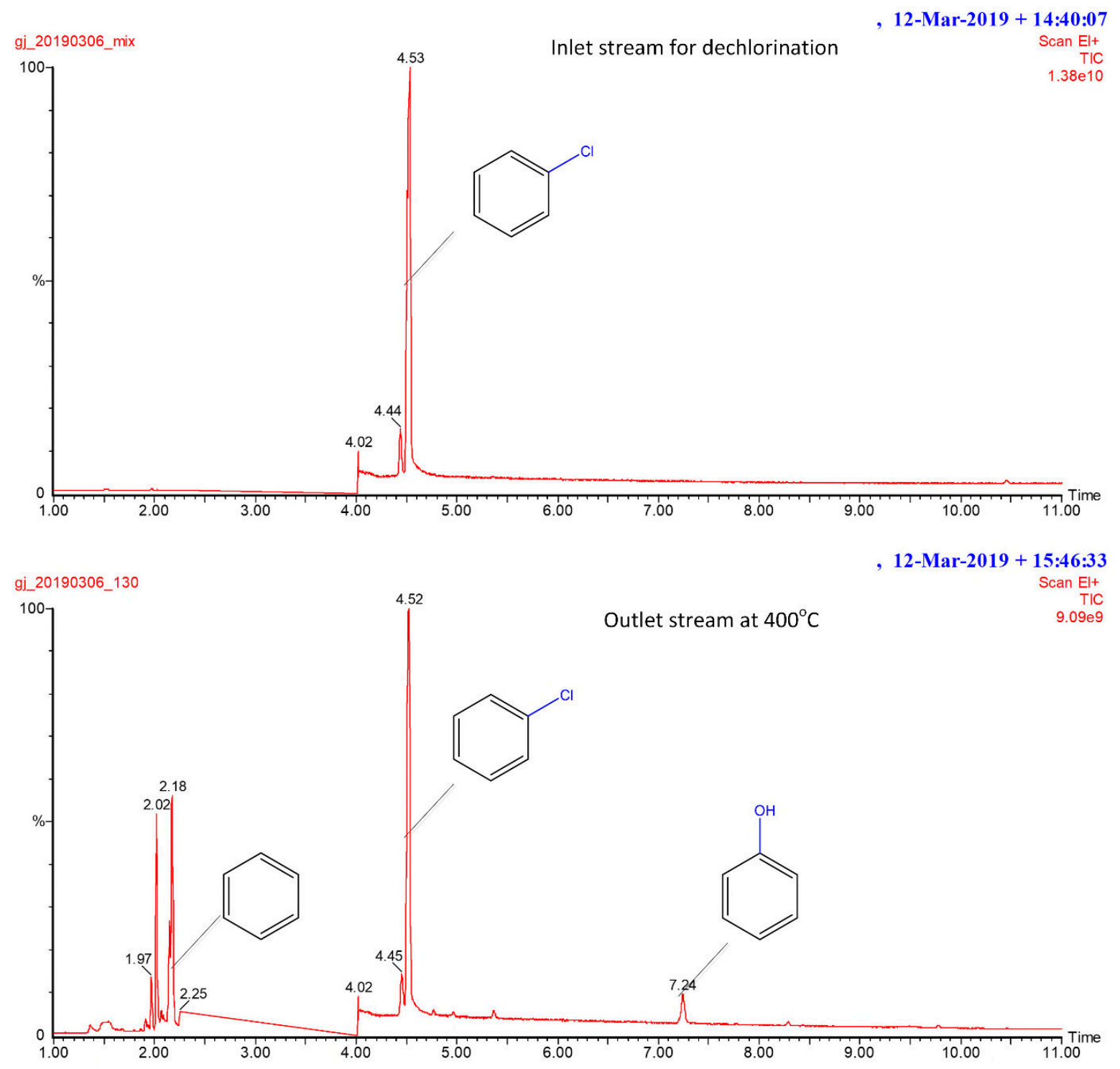

Figure 6. GCMS chromatogram of inlet and outlet stream for the adsorption of chlorobenzene at $400^{\circ} \mathrm{C}$. The liquid flow rate was $2 \mathrm{ml} / \mathrm{min}$. Initial concentration of chlorobenzene was $10000 \mathrm{ppm}$ (wt).

In order to further confirm the effects of alumina, $\mathrm{CaCO}_{3}$ was used to conduct similar experiments to those of $\mathrm{Na}_{2} \mathrm{CO}_{3}$. It can be seen in Figure 7 that $\mathrm{CaCO}_{3}$ alone does not dechlorinate chlorobenzene. When $\mathrm{CaCO}_{3}$ and alumina were used together, chlorobenzene was dechlorinated. For $\mathrm{CaCO}_{3}$, the dechlorination starts at about $400^{\circ} \mathrm{C}$, which is about $80^{\circ} \mathrm{C}$ higher than that of $\mathrm{Na}_{2} \mathrm{CO}_{3}$. It should be noted that breakthrough does not appear for $\mathrm{CaCO}_{3}$ since the 
bed contains more than double the amount of alkali in order to observe the effect of varying alkali amount.

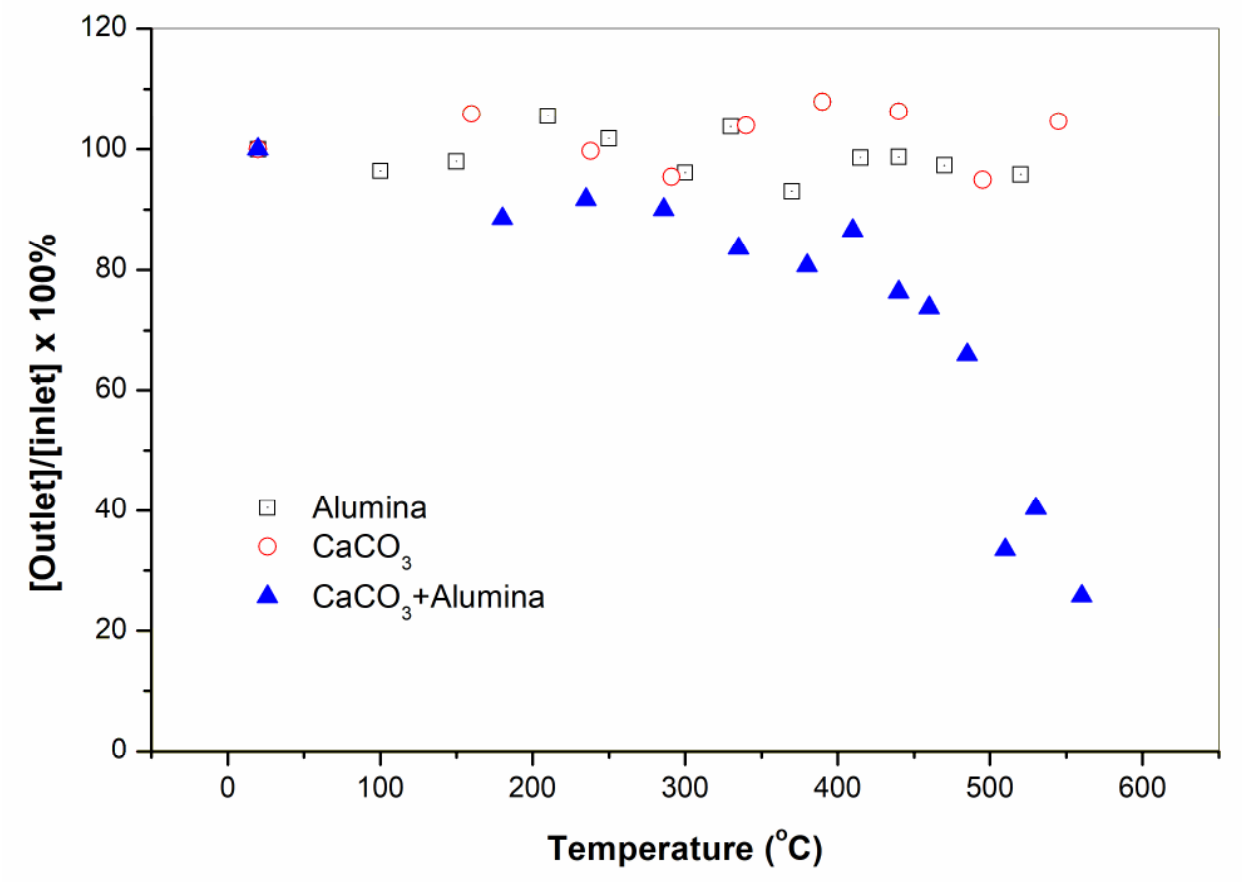

Figure 7. Dechlorination of chlorobenzene over different adsorption beds and temperatures. The concentration of chlorobenzene in isooctane was 10000 ppm (wt.). The inlet liquid flow rate was $2 \mathrm{ml} / \mathrm{min}$. The bed consisted of $6 \mathrm{~g} \mathrm{CaCO} 3$ or $12 \mathrm{ml}(4.7 \mathrm{~g})$ alumina or their mixture.

The IR spectra of the $\mathrm{Na}_{2} \mathrm{CO}_{3}$ before and after the adsorption experiments are shown in Figure 8. $\mathrm{Na}_{2} \mathrm{CO}_{3}$ has three characteristic adsorption band at 1417,877 and $702 \mathrm{~cm}^{-1}$, which are attributed to in-, out-plane bending and asymmetrical stretching vibration of $\mathrm{O}-\mathrm{C}-\mathrm{O}$ bond, respectively. After the adsorption of chlorobenzene, the positions of these bands do not change, but the intensities decrease significantly. It is well known that the band intensity is dependent upon the concentration. This indicates the concentration of O-C-O bond decreases after adsorption of chlorobenzene, and thus some $\mathrm{Na}_{2} \mathrm{CO}_{3}$ is consumed. From the IR spectra, the conversion of $\mathrm{Na}_{2} \mathrm{CO}_{3}$ is about $40 \%$ (atom basis) after the breakthrough point is reached. It can be inferred that a dispersion of alkali on a large surface carrier may enhance the efficiency of the adsorbent. It can also be seen that there are no new adsorption bands after the experiment. 
Figure 9 shows the IR spectra of the $\mathrm{CaCO}_{3}$ before and after the adsorption experiments. Similar to $\mathrm{Na}_{2} \mathrm{CO}_{3}$, the adsorption band at 1417,877 and $702 \mathrm{~cm}^{-1}$ for the O-C-O bond becomes weaker. However, two bands appear at $820 \mathrm{~cm}^{-1}$ and $699 \mathrm{~cm}^{-1}$, which are attributed to the IR adsorption of $\mathrm{CaCl}_{2}$, suggesting the formation of $\mathrm{CaCl}_{2}$ following the adsorption of chlorobenzene.

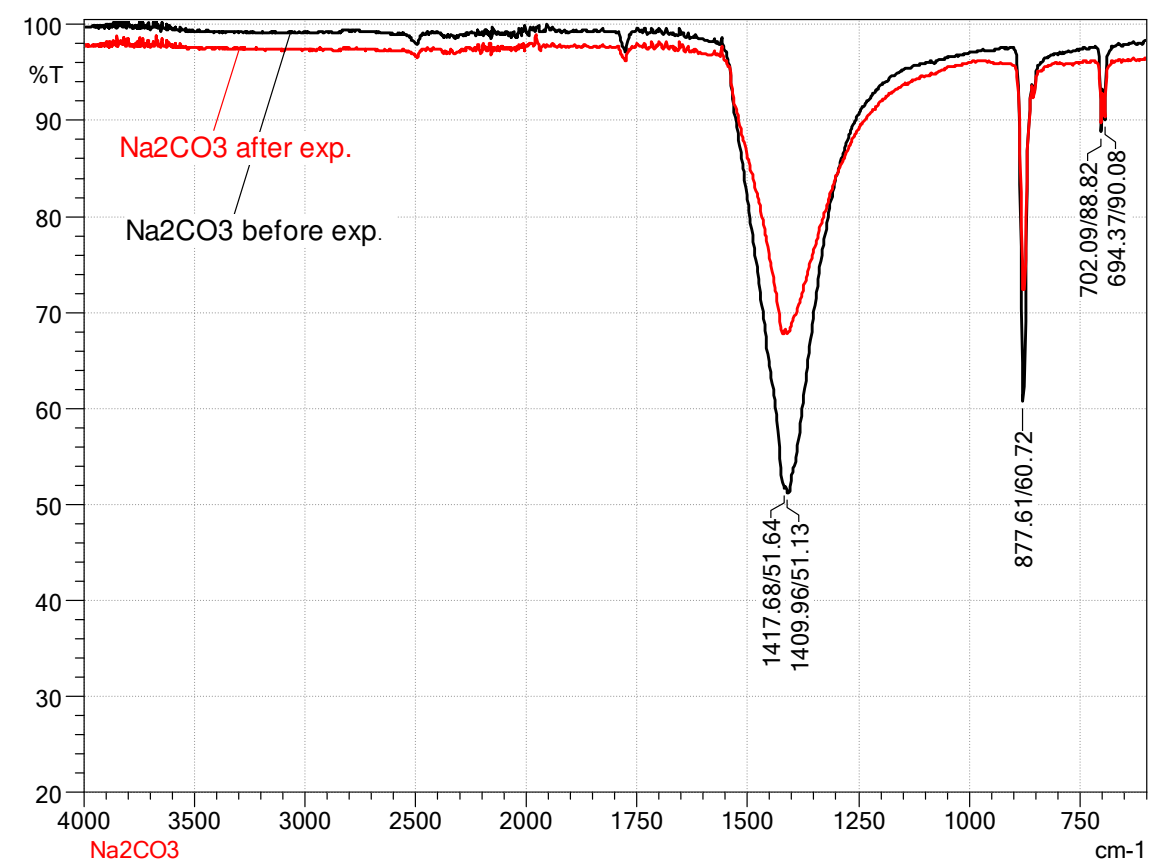

Figure 8. IR spectra of the adsorbent $\mathrm{Na}_{2} \mathrm{CO}_{3}$ before and after adsorption of chlorinated hydrocarbons. The adsorbate was chlorobenzene in isooctane (10000ppm by wt.). 


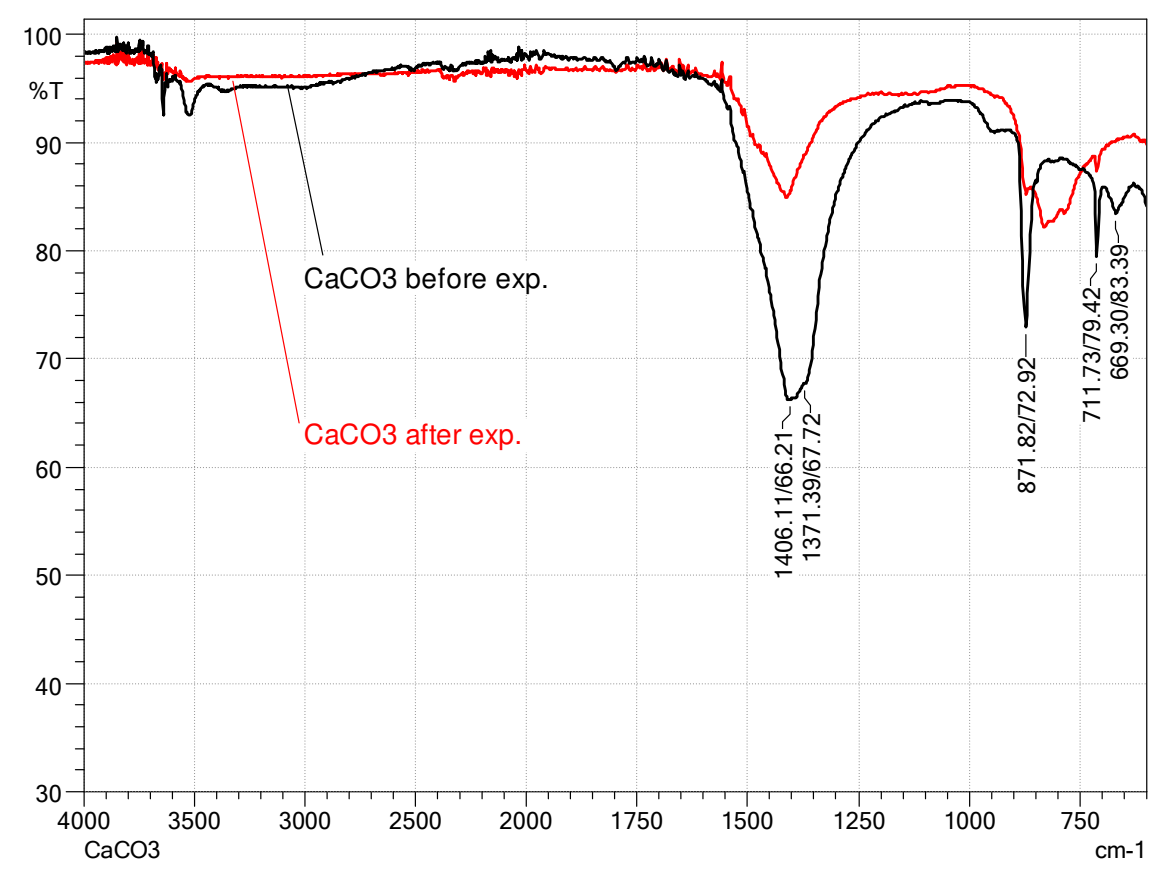

Figure 9. IR spectra of the adsorbent $\mathrm{CaCO}_{3}$ before and after adsorption of chlorinated hydrocarbons. The adsorbate was chlorobenzene in isooctane (10000 ppm by wt.).

The alkali after the adsorption experiment were further characterised using XRD. The XRD pattern is shown in Figure 10 for the $\mathrm{Na}_{2} \mathrm{CO}_{3}$ and in Figure 11 for $\mathrm{CaCO}_{3}$ after adsorption of chlorobenzene. It can be seen that the XRD pattern contains both diffraction peaks for $\mathrm{Na}_{2} \mathrm{CO}_{3}$ and $\mathrm{NaCl}$ for $\mathrm{Na}_{2} \mathrm{CO}_{3}$ as the adsorbent, and $\mathrm{CaCO}_{3}$ and $\mathrm{CaCl}_{2}$ for $\mathrm{CaCO}_{3}$ as the adsorbent. Clearly, the $\mathrm{Na}_{2} \mathrm{CO}_{3}$ phase is partially converted to $\mathrm{NaCl}$, which is consistent with the IR analysis, since $\mathrm{NaCl}$ is IR transparent. The $\mathrm{CaCO}_{3}$ is converted to $\mathrm{CaCl}_{2}$, which is also consistent with the IR analysis. 


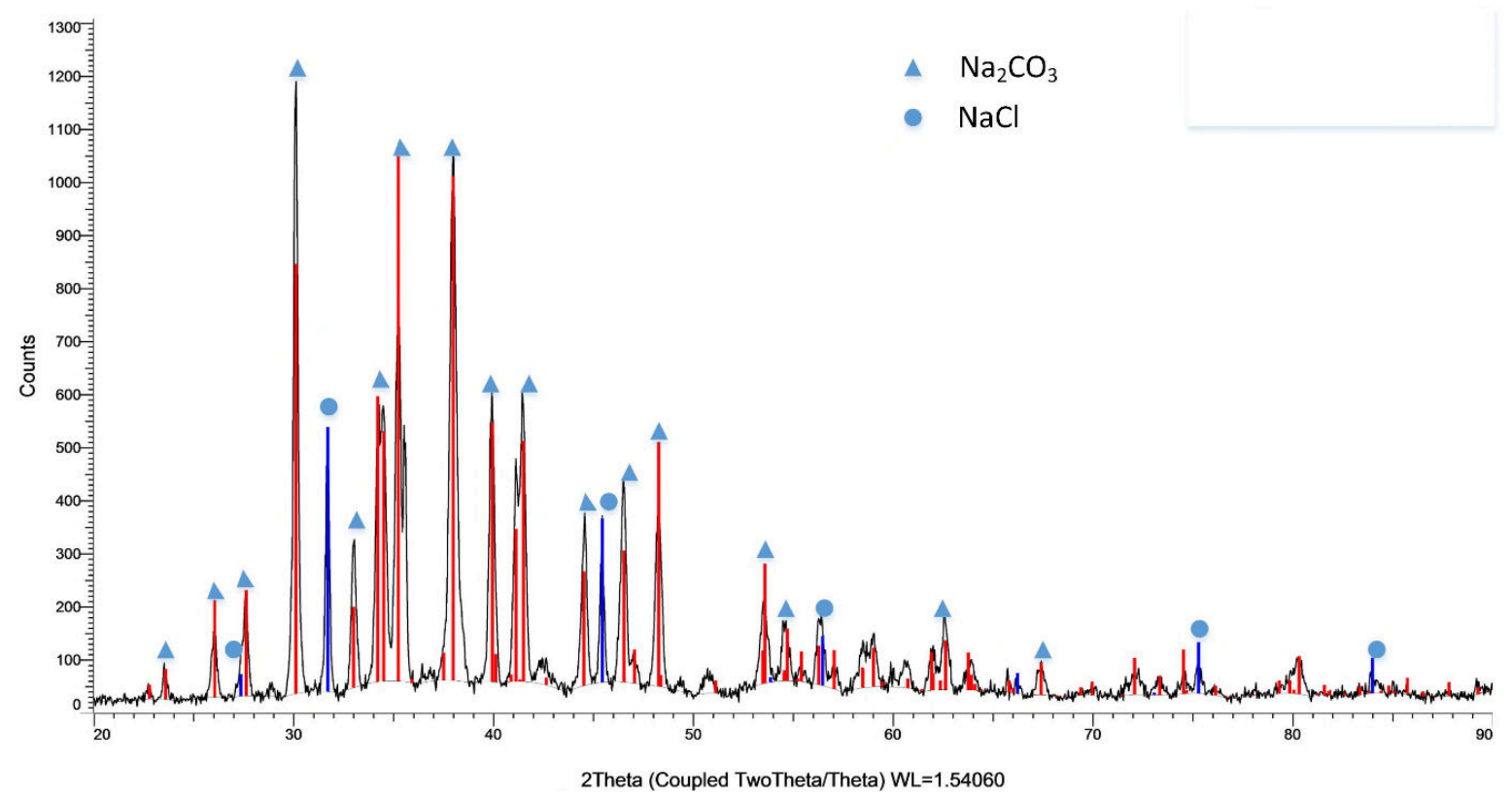

Figure 10. XRD diffraction pattern for $\mathrm{Na}_{2} \mathrm{CO}_{3}$ after absorption of chlorobenzene.

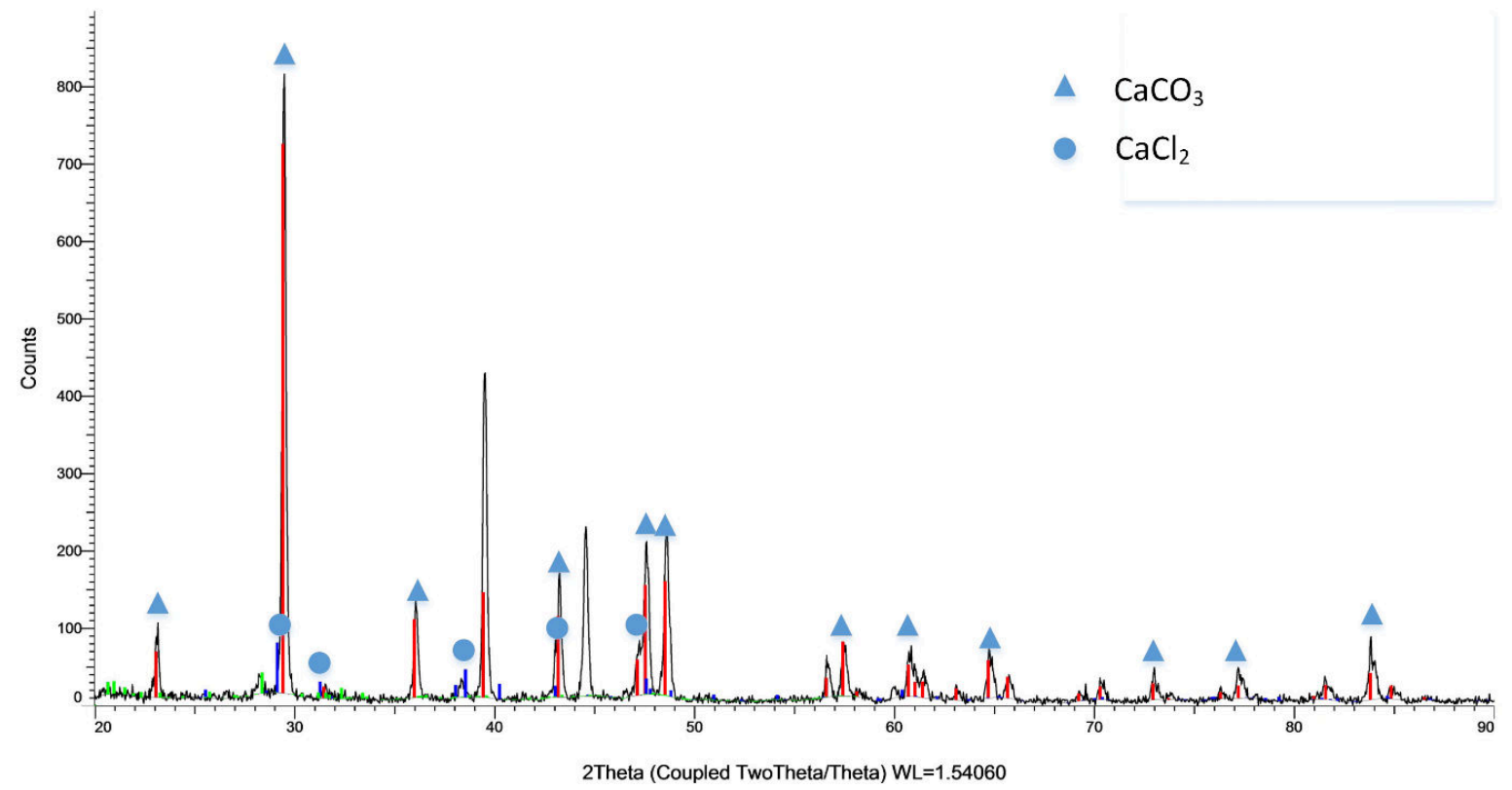

Figure 11. XRD diffraction pattern for $\mathrm{CaCO}_{3}$ after absorption of chlorobenzene.

The XRD diffraction patterns of the fresh and used alumina are shown in Figure 12. The fresh alumina has three main broad diffraction peaks at $37.59^{\circ}, 44.48^{\circ}, 45.84^{\circ}$, and $67.00^{\circ}$, which are 
characteristic of $\gamma$-alumina. ${ }^{30}$ The XRD diffraction pattern of the alumina used with $\mathrm{Na}_{2} \mathrm{CO}_{3}$ has characteristic diffraction peaks of alumina. However, some distinguished carbon diffraction peaks at $27.28^{\circ}, 31.63^{\circ}, 45.33^{\circ}, 75.16^{\circ}$, and $78.16^{\circ}$ is superposed over alumina. ${ }^{31}$ The alumina used with $\mathrm{CaCO}_{3}$ also has characteristic diffraction peaks of alumina, but has much weak carbon peaks superposed over alumina, which may be due to the less carbon on the surface originating from coke produced from hydrocarbon cracking. ${ }^{32}$. The XRD pattern of the used and fresh alumina indicates that the structure of alumina is not changed during the adsorption. 

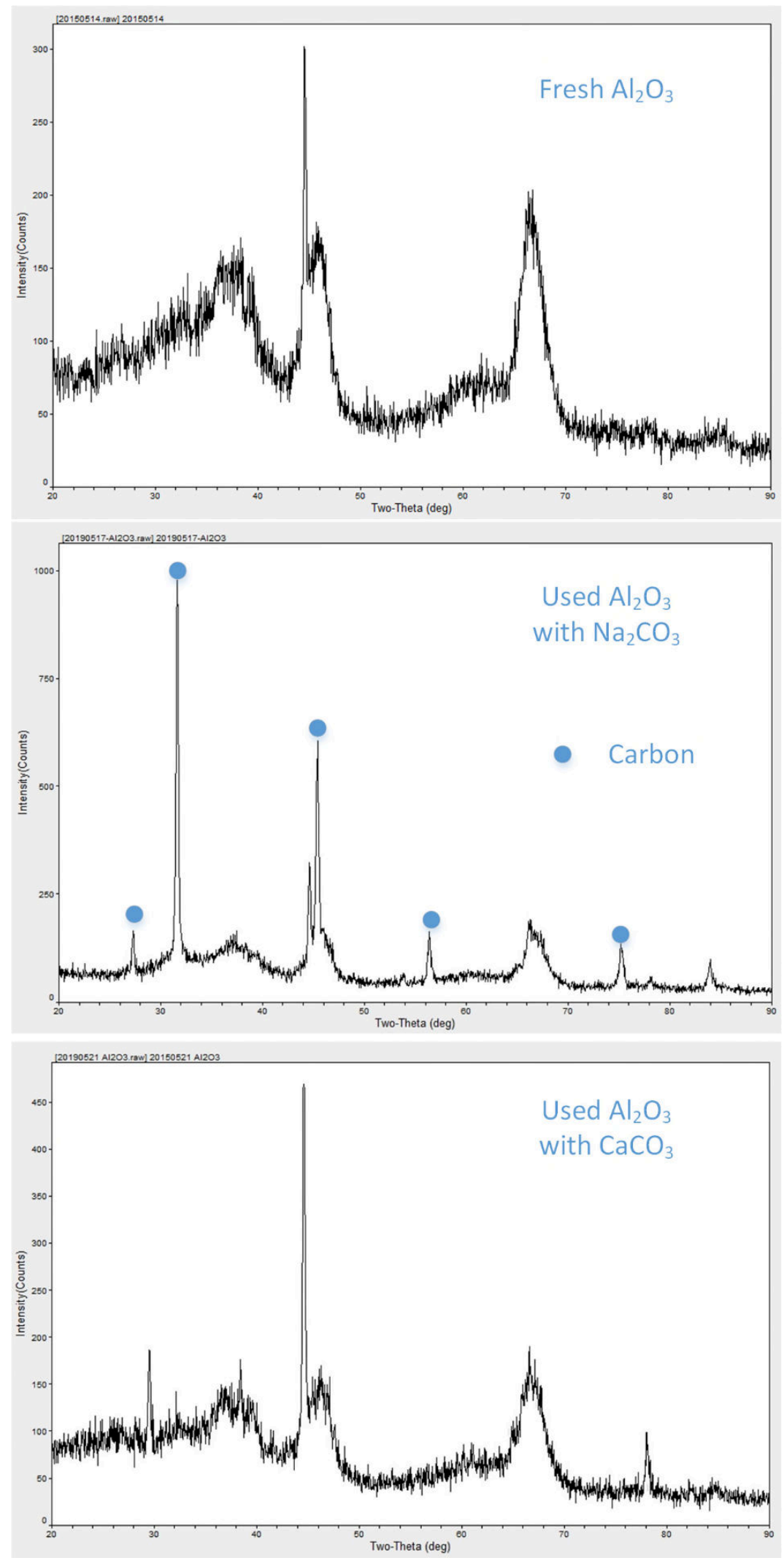
Figure 12. XRD patterns of the fresh and used alumina with $\mathrm{Na}_{2} \mathrm{CO}_{3}$ and $\mathrm{CaCO}_{3}$ absorbents.

\section{Mechanism of the adsorption of chlorobenzene}

The results showed that both $\mathrm{Na}_{2} \mathrm{CO}_{3}$ and $\mathrm{CaCO}_{3}$ alone cannot dechlorinate chlorobenzene at a temperature below $550^{\circ} \mathrm{C}$, which is consistent with the literature reports. ${ }^{27,}{ }^{29} \mathrm{In}$ contrast, the dechlorination occurred at much higher temperatures of 700 to $900^{\circ} \mathrm{C}$ in those reports. ${ }^{27,}{ }^{29} \mathrm{In}$ addition, this work showed that alumina alone cannot crack chlorobenzene below $550^{\circ} \mathrm{C}$. However, the dechlorination reaction occurred when alumina and an alkali were used together. It is well known that alumina can catalyse the cracking of hydrocarbons via a carbocation mechanism. ${ }^{28}$ The cracking of isooctane can be seen in the chromatogram for the adsorption of chlorobenzene at $450^{\circ} \mathrm{C}$ as shown in Figure 3. The dechlorination of chlorobenzene is promoted in this ionic environment, implying that the breaking of $\mathrm{C}-\mathrm{Cl}$ bond has also an ionic nature, and consequently, can be facilitated by the ion species formed from the isooctane cracking on the alumina.

Furthermore, the adsorption capacity of the alkali adsorbents $\left(\mathrm{Na}_{2} \mathrm{CO}_{3}\right.$ and $\left.\mathrm{CaCO}_{3}\right)$ toward chlorobenzene is much smaller when compared with the adsorption of 2-chloroethylbenzene. This indicates that the interior of the alkalis can be used for the adsorption of 2chloroethylbenzene, but not for chlorobenzene. The dechlorination of chlorobenzene proceeded only on the surface.

The sizes of the molecules involved in the adsorption were estimated according to their densities and molar masses using Equation 2, and the results are presented in Table 1.

$$
D=\sqrt[3]{\frac{M}{\rho N_{A}}}
$$

Where $\mathrm{M}$ is the molar mass $(\mathrm{kg} / \mathrm{kmol}), \rho$ is the density $\left(\mathrm{kg} / \mathrm{m}^{3}\right)$, and $\mathrm{N}_{\mathrm{A}}$ is the Avogadro constant $\left(6.023 \times 10^{23} / \mathrm{mol}\right)$. 
Table2. Estimated molecular size of the chlorinated hydrocarbons and $\mathrm{HCl}$.

\begin{tabular}{|lllll|}
\hline Molecules & $\begin{array}{l}\text { Density } \\
\left(\mathrm{kg} / \mathrm{m}^{3}\right)\end{array}$ & $\begin{array}{l}\text { Molar mass } \\
(\mathrm{kg} / \mathrm{kmol})\end{array}$ & $\begin{array}{l}\text { Volume/molecule } \\
\left(\AA^{3}\right)\end{array}$ & $\begin{array}{l}\text { Molecule } \\
\text { size }(\AA)\end{array}$ \\
\hline chlorobenzene & 1110 & 112.56 & 168.36 & 5.52 \\
\hline 2-chlorobutane & 873 & 92.57 & 176.05 & 5.60 \\
\hline 2-chloroethylbenzene & 1069 & 140.61 & 218.39 & 6.02 \\
\hline $\mathrm{HCl}$ & 1490 & 36.46 & 40.63 & 3.43 \\
\hline
\end{tabular}

As shown in Table 2, the three chlorinated hydrocarbons have similar size, while the size of $\mathrm{HCl}$ is about half of those chlorinated hydrocarbons. If the adsorption of all these chlorinated hydrocarbons proceeded by direct interaction with the adsorbents, their adsorption behaviour would be similar. The much greater adsorption capacity for both 2-chlorobutane and 2chloroethylbenzene can be attributed to the rapid alkali adsorption of $\mathrm{HCl}$ formed via dehydrochlorination, while the dechlorination of chlorobenzene occurred by direct interaction of the alkali and chlorobenzene, which was not able to access the interior of the alkali because of its larger molecular size compared with $\mathrm{HCl}$. It can be inferred that $\mathrm{HCl}$ would be able to access the interior of the adsorbents, and this can be observed by Torres et al.'s work. ${ }^{33}$

Based on the above inference, the dechlorination of chlorobenzene in the presence of alumina and isooctane is shown in Scheme 5. At first, a carbocation species $\mathrm{R}^{+}$formed from cracking isooctane attaches the negatively charged chlorine of chlorobenzene, making the carbon of the $\mathrm{C}$ $\mathrm{Cl}$ bond more positively charged, which facilitates the attacking of the negatively charged oxygen of $\mathrm{Na}_{2} \mathrm{CO}_{3}$, to break the $\mathrm{C}-\mathrm{Cl}$ bond forming $\mathrm{NaCl}$ and a phenyl cation. The pathway of forming $\mathrm{R}-\mathrm{Cl}$ and a phenyl cation should not occur since this will lead to the same reaction mechanism as that of aliphatic chlorinated hydrocarbons, but on the contrary thus occurs according to our work. The phenyl cation may then abstract a surface hydroxyl group on the surface of the adsorbent to form phenol or abstract hydrogen from isooctane to form benzene. The hydroxyl group may come from the moisture on the surface, since the production of phenol disappeared at later stages of the adsorption, as shown in Figure S7 for the evolution of benzene and phenol in the adsorption. The overall effect of this mechanism is similar to the $\mathrm{Cl}^{-} / \mathrm{O}^{2}$ ion 
exchange mechanism proposed by Li et al. ${ }^{27}$, but the authors did not illustrate how the exchange took place.

As shown in Table 1, the calculation of the mass of the $\mathrm{Na}_{2} \mathrm{CO}_{3}$ adsorbent according to a simple exchange of $\mathrm{O}$ and $\mathrm{Cl}$ does not match the actual mass change. This indicates that some further reaction such as formation of $\mathrm{CO}_{2}$ may occur after replacement of one oxygen of $\mathrm{Na}_{2} \mathrm{CO}_{3}$ with chlorine.

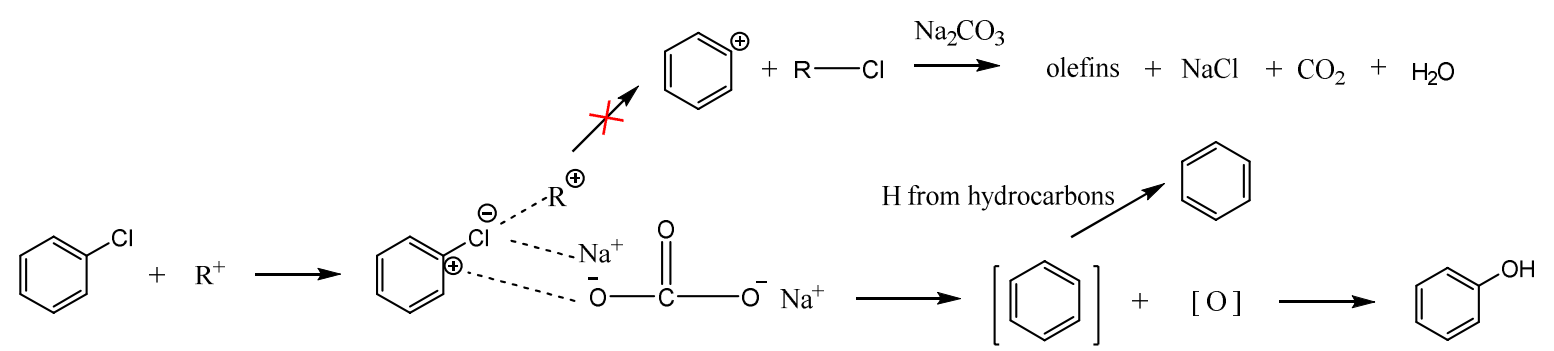

Scheme 5. Proposed reaction mechanism for dechlorination of chlorobenzene

This mechanism has strong implications for the removal of chlorine from the pyrolysis of mixed plastics containing PVC. This study indicates that the key to dechlorinate pyrolysis vapour is to dechlorinate aromatic chlorinated hydrocarbons, which proceeds on the surface of adsorbents and requires higher temperature. The dechlorination of aliphatic chlorinated hydrocarbons is relatively easy, which can be implemented at much lower temperature, and has a nature of acidbase neutralization, as shown in Schemes 3 and 4. It can be inferred that alkaline substances supported on a solid acidic carrier with large pore size may be used to remove both aliphatic and aromatic chlorinated hydrocarbons. For example, the pore size of the adsorbent should be greater than $5.5 \AA$ for adsorption of chlorobenzene, such as 10A or mesoporous zeolites used as the carrier.

\section{CONCLUSIONS}

In this work, the mechanism of dechlorination of chlorinated hydrocarbons is investigated by the adsorption on alkali adsorbents. 2-Chlorobutane, 2-chloroethylbenzene and chlorobenzene doped in isooctane were used to model the pyrolysis vapour containing chlorinated hydrocarbons. The following conclusions can be drawn. 
Two mechanisms are operating for the dechlorination of chlorinated hydrocarbons. For aliphatic chlorinated hydrocarbons that contain aliphatic hydrogen adjacent to the chlorine atom, the pathway for dechlorination is via the dehydrochlorination of the chlorinated compound resulting in the formation of olefins and $\mathrm{HCl}$. The reaction is driven to completion by the in situ removal of the $\mathrm{HCl}$ through its reaction with the alkali in the adsorbent. After adsorption, the alkali is converted to the corresponding metal chloride. This reaction can be carried out as low as $180^{\circ} \mathrm{C}$.

The dechlorination of aromatic chlorinated hydrocarbons, such as chlorobenzene is much more difficult than that of aliphatic chlorinated hydrocarbons. In the presence of alumina and isooctane, the dechlorination can be achieved at around $300^{\circ} \mathrm{C}$, due to the enhancing effect of the ionic intermediate produced by cracking of the hydrocarbon.

\section{ACKNOWLEDGEMENTS}

The authors thank the Department of Business, Energy and Industrial strategy (BEIS) UK for financially supporting this research through the Energy Entrepreneur Fund 5. We also thank Recycling Technologies Ltd for their useful advice during the work. RT is thankful for the H2020 SME Innovation Programme and the European Commission for training in industrial innovation management.

\section{REFERENCES}

1. Kaminsky, W., Chemical recycling of mixed plastics by pyrolysis. Adv. Polym. Technol. 1995, 14, 337-344, DOI: 10.1002/adv.1995.060140407

2. Fukushima, M.; Shioya, M.; Wakai, K.; Ibe, H., Toward maximizing the recycling rate in a Sapporo waste plastics liquefaction plant. J. Mater. Cycles Waste Manag. 2009, 11, 11-18, DOI: 10.1007/s10163-008-0212-6

3. Kumagai, S.; Toshioka, T., Feedstock recycling via waste plastic pyrolysis. J. Japan Pet. Inst. 2016, 59, 243-253, DOI: 10.1627/jpi.59.243

4. Westerhout, R. W. J.; van Koningsbruggen, M. P.; van der Ham, A. G. J.; Kuipers, J. A. M.; van Swaaij, W. P. H., Techno-economic evaluation of high temperature pyrolysis processes for mixed plastic waste. Trans. Inst. Chem. Eng. 1998, 76, 427-439, DOI: 10.1205/026387698524857

5. Fonseca, J. D.; Grause, G.; Kameda, T.; Yoshioka, T., Effects of steam on the thermal dehydrochlorination of poly(vinylchloride) resin andflexible poly(vinyl chloride) under atmosphericpressure. Polym. Degrad. Stab. 2015, 117, 8-15, DOI:

10.1016/j.polymdegradstab.2015.03.011

6. Hapipi, A. M.; Suda, H.; Uddin, M. A.; Kato, Y., Dechlorination of polyvinyl chloride under superheated steam with catalysts and adsorbents. Energy Fuels 2018, 32, 7792-7799, DOI: 10.1021/acs.energyfuels.8b00838 
7. Nishibata, H.; Uddin, M. A.; Kato, Y., Simultaneous degradation and dechlorination of poly (vinyl chloride) by a combination of superheated steam and CaO catalyst/adsorbent. Polym. Degrad. Stab.

2020, 179, Article 109225, DOI: 10.1016/j.polymdegradstab.2020.109225

8. Kameda, T.; Ono, M.; Grause, G.; Mizoguchi, T.; Yoshioka, T., Ball Mill-Assisted Dechlorination of Flexible and Rigid Poly(vinyl chloride) in $\mathrm{NaOH}$ /EG Solution. Ind. Eng. Chem. Res. 2008, 47, 8619-8624, DOI: 10.1021/ie8006819

9. Yoshioka, T.; Kameda, T.; Imai, S.; Okuwaki, A., Dechlorination of poly(vinyl chloride) using $\mathrm{NaOH}$ in ethylene glycol under atmospheric pressure. Polym. Degrad. Stab. 2008, 93, 1138-1141, DOI: 10.1016/j.polymdegradstab.2008.03.007

10. Zakharyan, E. M.; Petrukhina, N. N.; Maksimov, A. L., Pathways of Chemical Recycling of Polyvinyl Chloride: Part 1. Russ. J. Appl. Chem. 2020, 93, 1271-1313, DOI: 10.1134/S1070427220090013

11. Hinz, B.; Hoffmockel, M.; Pohlmann, K.; Schadel, S.; Schimmel, I.; Sinn, H., Dehalogenation of pyrolysis products. J. Anal. Appl. Pyrolysis 1994, 30, 35-46, DOI: 10.1016/0165-2370(94)00800-0

12. Cho, M.-H.; Jung, S.-H.; Kim, J.-S., Pyrolysis of mixed plastics wastes for the recovery of benzene, toluene and xylene aromatics in a fluidized bed and chlorine removal by applying various additives.

Energy Fuels 2010, 24, 1389-1395, DOI: 10.1021/ef901127v

13. Bhaskar, T.; Matsui, T.; Kaneko, J.; Uddin, M. A.; Muto, A.; Sakata, Y., Novel calcium based sorbent $(\mathrm{Ca}-\mathrm{C})$ for the dehalogenation $(\mathrm{Br}, \mathrm{Cl})$ process during halogenated mixed plastic (PP/PE/PS/PVC and HIPS-Br) pyrolysis. Green Chem. 2002, 4, 372-375, DOI: 10.1039/B203745A

14. Bie, R.; Li, S.; Yang, L., Reaction mechanism of $\mathrm{CaO}$ with $\mathrm{HCl}$ in incineration of wastewater in fluidized bed. Chem. Eng. Sci. 2005, 60, 609-616, DOI: 10.1016/j.ces.2004.08.022

15. Daoudi, M.; Walters, J. K., The reaction of $\mathrm{HCl}$ gas with calcined commercial limestone particles: The effect of particle size. Chem. Eng. J. 1991, 47, 11-16, DOI: 10.1016/0300-9467(91)85002-D

16. Lingaiah, N.; Uddin, M. A.; Muto, A.; Sakata, Y.; Imai, T.; Murata, K., Catalytic dechlorination of chloroorganic compounds from PVC-containing mixed plastic-derived oil. Appl. Catal., A 2001, 207, 79-

84, DOI: 10.1016/S0926-860X(00)00656-6

17. Lingaiah, N.; Lingaiah, N.; Uddin, M. A.; Morikawa, K.; Muto, A.; Murata, K.; Sakata, Y., Catalytic dehydrochlorination of chloro-organic compounds from PVC containing waste plastics derived fuel oil over FeCl2/SiO2 catalyst. Green Chem. 2001, 3, 74-75, DOI: 10.1039/B0094710

18. Lingaiah, N.; Uddin, M. A.; Muto, A.; Imai, T.; Sakata, Y., Removal of organic chlorine compounds by catalytic dehydrochlorination for the refinement of municipal waste plastic derived oil.

Fuel 2001, 80, 1901-1905, DOI: 10.1016/S0016-2361(01)00046-1

19. Uddin, M. A.; Sakata, Y.; Shiraga, Y.; Muto, A.; Katsuhide, M., Dechlorination of chlorine compounds in poly(vinyl chloride) mixed plastics derived oil by solid sorbents. Ind. Eng. Chem. Res. 1999, 38, 1406-1410, DOI: 10.1021/ie980445k

20. Lopez-Urionabarrenechea, A.; Marco, I.; Caballero, B. M.; Laresgoiti, M. F.; Adrados, A., Upgrading of chlorinated oils coming from pyrolysis of plastic waste. Fuel Process. Technol. 2015, 137, 229-239, DOI: 10.1016/j.fuproc.2015.04.015

21. McNeill, I. C.; Memetea, L.; Cole, W. J., A study of the products of PVC thermal degradation. Polym. Degrad. Stab. 1995, 49, 181-191, DOI: 10.1016/0141-3910(95)00064-S

22. Miranda, R.; Yang, J.; Roy, C.; Vasile, C., Vacuum pyrolysis of PVC. I. Kinetic study. Polym. Degrad. Stab. 1999, 64, 127-144, DOI: 10.1016/S0141-3910(98)00186-4

23. Miranda, R.; Pakdel, H.; Roy, C.; Hans, D.; Vasile, C., Vacuum pyrolysis of PVC II: Product analysis. Polym. Degrad. Stab. 1999, 66, 107-125, DOI: 10.1016/S0141-3910(01)00066-0

24. Bej, S. K.; Dalai, A. K.; Maity, S. K., Effect of diluent size on the performance of a micro-scale fixed bed multiphase reactor in up flow and down flow modes of operation. Catal. Today 2001, 64, 333345, DOI: 10.1016/S0920-5861(00)00536-8 
25. Moene, R.; Makkee, M.; Moulijn, J. A., High surface area silicon carbide as catalyst support characterization and stability. Appl. Catal., A 1998, 167, 321-330, DOI: 10.1016/S0926-860X(97)00326-8

26. Cullis, C. F.; Manton, J. E., The pyrolysis of chlorobenzene. J. Chem. Soc. Faraday Trans. 1958, 54, 381-389, DOI: 10.1039/TF9585400381

27. Li, Y.-X.; Li, H.; Klabunde, K. J., Destructive adsorption of chlorinated benzenes on ultrafine (nanoscale) particles of magnesium oxide and calcium oxide. Environ. Sci. Technol. 1994, 28, 1248-1253, DOI: 10.1021/es00056a011

28. Westrich, T. A.; Chen, X.; Schwank, J. W., Isooctane decomposition and carbon deposition over ceria-zirconia supported nickel catalysts. Appl. Catal., A 2010, 386, 83-93, DOI:

10.1016/j.apcata.2010.07.029

29. Parrett, J. W.; Sumner, J. P.; Devore, T. C., Reaction between chlorocarbon vapors and sodium carbonate. Environ. Sci. Technol. 1999, 33, 1691-1696, DOI: 10.1021/es980077b

30. Rozita, Y.; Brydson, R.; Scott, A. J., An investigation of commercial gamma-Al $\mathrm{O}_{3}$ nanoparticles. J. Phys. Conf. Ser. 2009, 241, article \# 012096, DOI: 10.1088/1742-6596/241/1/012096

31. Ungar, T.; Gubicza, J.; Ribarik, G.; Pantea, C.; Zerda, T. W., Microstructure of carbon blacks determined by X-ray diffraction profile analysis. Carbon 2002, 40, 929-937, DOI: 10.1016/S00086223(01)00224-X

32. Sinfelt, J. H.; Rohrer, J. C., Cracking of hydrocarbons over a promoted alumina catalyst. J. Phys. Chem. 1962, 66, 1559-1560, DOI: doi.org/10.1021/j100814a516

33. Torres, D.; Jiang, Y.; Sanchez-Monsalve, D. A.; Leeke, G. A., Hydrochloric acid removal from the thermogravimetric pyrolysis of PVC. J. Anal. Appl. Pyrolysis 2020, 149, \#104831, DOI:

10.1016/j.jaap.2020.104831 


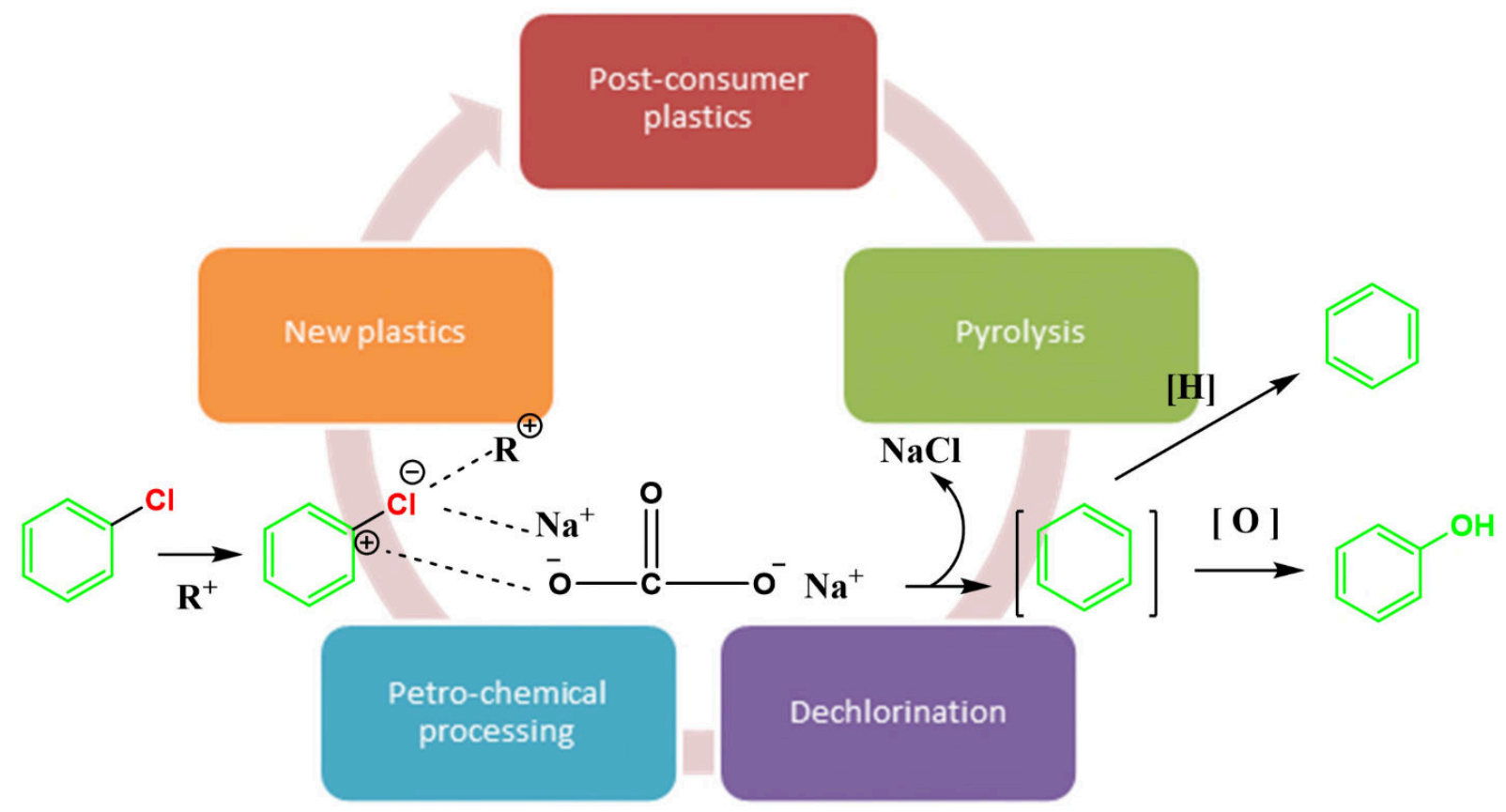

\section{SYNOPSIS}

The mechanism of dechlorination of chlorinated hydrocarbons was explored for producing qualified plastic oil as petrochemical feedstock. 